\title{
Confirming the Functional Importance of a Protein-DNA Interaction
}

\author{
Michael F. Carey, Craig L. Peterson, and Stephen T. Smale
}

\begin{abstract}
Identifying DNA-binding proteins that interact with a control region of interest has become quite straightforward. However, the functional relevance of a given protein-DNA interaction is difficult to establish. The hypothesis that an interaction is relevant can be tested by several different experiments, 12 of which are outlined in this article. It must be remembered that none of these experiments by itself is conclusive. The information gained from each approach is described and explanations are given for why each yields useful but inconclusive results. The approaches vary widely with respect to the amount of effort required and the quality of information obtained.
\end{abstract}

\section{INTRODUCTION AND OVERVIEW}

In the modern era of molecular biology, identifying DNA-binding proteins that interact with a control region of interest is relatively straightforward, but establishing definitively that a specific transcription factor directly regulates a target gene by binding to a defined control element can be among the most difficult of tasks. There are experimental strategies to identify important DNA sequence elements, as well as proteins that bind those elements. In most instances, a transcription factor will have been implicated as a potential gene regulator by a TRANSFAC or JASPAR database search, by mass spectrometry analysis of proteins that bind the element in vitro, by a genome-wide chromatin immunoprecipitation (ChIP) analysis of a transcription factor's binding sites, or perhaps by a yeast onehybrid screen. The identification of candidate DNA-binding proteins provides a significant advance because it allows one to hypothesize that the protein is responsible for the function of the control element in regulating the nearby gene. By itself, however, identification does not prove biological relevance. For example, detecting a protein-DNA interaction in a nuclear extract reflects many factors: (1) the abundance of the protein in the cells from which the extract was prepared, (2) the efficiency with which the protein was extracted from the cells, (3) the stability of the active protein within the extract, (4) the maintenance of essential posttranslational modifications during extract preparation, (5) the conditions used for the in vitro DNA-binding assay, and (6) the affinity of the protein for the isolated control element (Table 1).

The criteria for detecting protein-DNA interactions in vitro are very different from those that determine which protein interacts functionally with the control element in vivo (i.e., which protein regulates the endogenous gene by binding to the control element) (Table 1). These criteria include (1) the abundance and stability of the protein in the cell nucleus, (2) the affinity of the protein for the site, (3) the ability of the protein to perform appropriate interactions with other proteins bound to adjacent

Adapted from Transcriptional Regulation in Eukaryotes: Concepts, Strategies, and Techniques, 2nd edition, by Michael F. Carey, Craig L. Peterson, and Stephen T. Smale. CSHL Press, Cold Spring Harbor, NY, USA, 2009.

(C) 2012 Cold Spring Harbor Laboratory Press

Cite this article as Cold Spring Harb Protoc; 2012; doi:10.1101/pdb.top070060 
TABLE 1. Factors that influence the in vitro detection and in vivo relevance of protein-DNA interactions

\begin{tabular}{ll}
\hline Detection in vitro & Functional relevance in vivo \\
\hline Abundance of protein in cell & Abundance and stability of protein in cell nucleus \\
Efficiency of protein extraction & Affinity of protein for the site \\
Stability of protein in extract & Ability of protein to interact appropriately with other proteins \\
Maintenance of essential posttranslational & Posttranslational modifications that allow the protein to \\
modifications during extract preparation & perform necessary interactions \\
Conditions used for in vitro DNA-binding assay & Appropriate subcellular and subnuclear localization of the \\
Affinity of the protein for the isolated control & protein element \\
\hline
\end{tabular}

sites and with non-DNA-binding cofactors, (4) appropriate posttranslational modifications that allow the protein to perform the necessary protein-DNA and protein-protein interactions, and (5) the appropriate subnuclear localization of the protein.

When considering the above points, it is readily apparent that detecting a protein-DNA interaction in vitro provides only weak evidence of its relevance in vivo, even when the DNA sequence element to which the protein binds is known to be important. A similar level of uncertainty exists when a protein capable of recognizing a DNA sequence element is identified in a TRANSFAC or JASPAR database search, as the consensus recognition sequences used to create those databases were determined using in vitro protein-DNA interaction assays. Most DNA-binding proteins can recognize a broad spectrum of DNA sequences with a wide range of affinities. Furthermore, most DNA-binding proteins are members of multiprotein families, with each cell type containing several family members that recognize similar DNA sequences. Based on these considerations, it is likely that multiple proteins will be capable of binding a defined control element in vitro, including several members of a particular protein family, and perhaps members of another family that recognize a similar or overlapping sequence. The challenge is to determine which of these proteins is capable of performing the protein-protein and protein-DNA interactions that allow it to regulate the endogenous gene. If by chance only one predominant DNA-binding protein is detected in vitro, or if a database search identifies only one candidate protein, it still may not be the one responsible for the function of the control element in vivo; other proteins within the cells are almost certainly capable of binding the same element, even if they were not detected in initial database analyses or electrophoretic mobilityshift assay (EMSA) studies.

A definitive approach for confirming the functional importance of a protein-DNA interaction in mammalian cells has not yet been developed. However, two powerful techniques have revolutionized efforts to evaluate the functional relevance of a DNA-binding protein that interacts with a DNA element of interest: ChIP and RNA interference (RNAi). Although both of these techniques were developed before the year 2000, they did not emerge as common methods for studying protein-DNA interactions in eukaryotic cells, in particular mammalian cells, until the 21st century.

As described below, ChIP has now become an extremely common method for monitoring the association of proteins with specific genomic regions in living cells. A positive result in a wellcontrolled ChIP experiment provides crucial information not obtainable previously: namely, that a candidate protein does indeed associate in close proximity to a control element of interest. This knowledge adds considerable strength to the hypothesis that a candidate DNA-binding protein is responsible for the function of a DNA element. However, ChIP is not a functional assay and merely shows an in vivo association. Because several studies suggest that DNA-binding proteins are not functionally active at all DNA elements they bind in vivo (see, e.g., Walter et al. 1994; Li and Johnston 2001; Martone et al. 2003; Phuc Le et al. 2005; Beima et al. 2006; Hollenhorst et al. 2007; Dong et al. 2008), additional evidence of functional relevance must be obtained.

Loss-of-function studies of a DNA-binding protein are critical for evaluating the functional importance of a protein-DNA interaction. However, until RNAi emerged as a common molecular biology tool, the methods available for performing such studies, particularly in mammalian cells, were either laborious (e.g., gene disruption by homologous recombination) or unpredictable, in that they 
had a relatively low probability of success (e.g., antisense RNA or dominant-negative methods). Using RNAi, it is now possible to rapidly knockdown the expression of the gene encoding almost any protein, as long as a cell population susceptible to RNAi is available. Unfortunately, despite its power, RNAi cannot easily overcome the limitations inherent in all loss-of-function approaches, including difficulties caused by redundancy between two or more factors and difficulties distinguishing direct from indirect effects.

To reiterate, although ChIP and RNAi have become two of the most useful methods for evaluating the relevance of a protein-DNA interaction, neither yields definitive results, and both possess considerable limitations. In the absence of a definitive experiment (i.e., an experiment that allows one to visualize directly a protein binding to a control element within its natural chromosomal location and regulating transcription of the linked gene), the only viable approach is to hypothesize that a proteinDNA interaction is relevant and then to subject that hypothesis to as many rigorous tests as possible, with ChIP and RNAi experiments serving as two of the more common and crucial tests. The point at which a hypothesis that a protein-DNA interaction is functionally important for regulating a gene of interest has been confirmed beyond a reasonable doubt depends on subjective evaluation and is therefore best left to the judgment of the scientific community.

This article presents 12 different approaches, beginning with ChIP and loss-of-function methods, that can be used to test whether a specific protein-DNA interaction is functionally important. We describe the information gained from each approach and explain why each yields useful but inconclusive results. The approaches vary widely with respect to the amount of effort required and the quality of information obtained. If a major goal is to establish the functional importance of an interaction, several different approaches should be pursued.

It is important to emphasize that a rigorous examination of the relevance of a transcription factorDNA interaction might not be an important objective of the investigator. The primary interest could instead be to determine whether a factor discovered during efforts to examine the regulation of a particular gene is important for a biological process. For example, even without strong evidence that the transcription factor regulates the gene of interest, it could itself have an interesting expression pattern that merits further exploration of its biological functions. In this instance, the next step is more obvious: The gene encoding the factor can be disrupted in a cell or animal, or gene expression can be reduced by RNAi. A comprehensive characterization of the knockout or knockdown phenotype can then be performed, including microarray experiments to identify genes that are misexpressed in the absence of the factor. If an interesting phenotype is observed, the investigator might begin a broadly based analysis of the factor, regardless of whether it interacts functionally with the control element used originally for its identification. This is a common and valid course of action. However, if the long-term goal is to link a protein to its relevant target genes, or to carefully dissect the mechanism by which a target gene is induced by a constellation of DNA-binding proteins, cofactors, and general transcription factors, the issues discussed in this article ultimately must be considered.

\section{EXPERIMENTAL STRATEGIES}

\section{Chromatin Immunoprecipitation}

One of the first experiments that is usually performed to test whether a specific DNA-binding protein is responsible for the function of a control region is a ChIP assay (Fig. 1). The precursor to the ChIP assay, which relied on ultraviolet crosslinking and Southern blot or dot-blot detection of immunoprecipitated DNA fragments, was developed by Gilmour and Lis to monitor RNA polymerase association with transcribed and poised genes in Escherichia coli and Drosophila (Gilmour and Lis 1984, 1985,1986 ). Contemporary ChIP assays, which usually rely on formaldehyde crosslinking of proteins to DNA (Solomon and Varshavsky 1985; Solomon et al. 1988; Braunstein et al. 1993; Orlando and Paro 1993; Orlando et al. 1997) and on PCR (polymerase chain reaction) detection of DNA fragments, were first used by Grunstein et al. to monitor histone modifications and the binding of SIR proteins in 


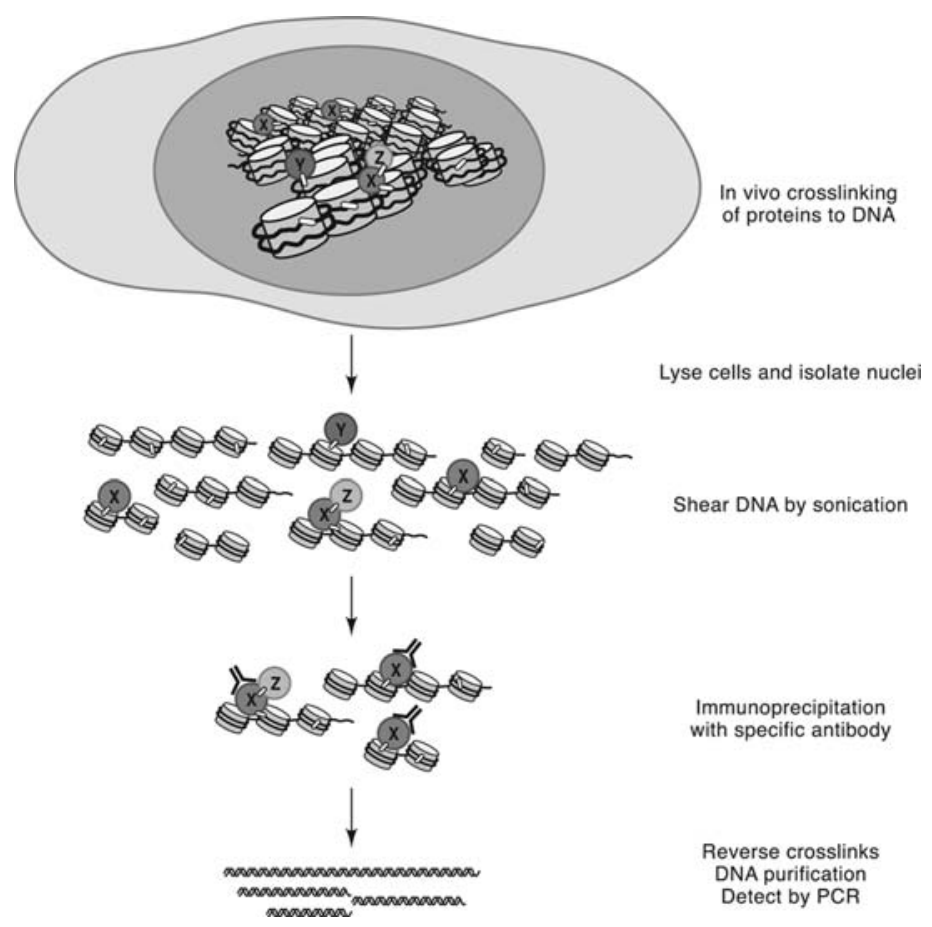

FIGURE 1. Chromatin immunoprecipitation.

Saccharomyces cerevisiae (see Hecht et al. 1996; Rundlett et al. 1998; Hecht and Grunstein 1999). The ChIP procedure was soon adapted for use in mammalian cells, first with ultraviolet crosslinking and subsequently with formaldehyde crosslinking (Boyd and Farnham 1997; Boyd et al. 1998; Wathelet et al. 1998; Parekh and Maniatis 1999).

In brief, growing cells are treated with formaldehyde to crosslink DNA-binding proteins to their target sites. The cells are then lysed and the DNA is cleaved into fragments by sonication and/or nuclease digestion. Protein-DNA complexes are purified by immunoprecipitation with antibodies directed against the DNA-binding protein of interest. To determine whether the protein is crosslinked to a putative target element, the crosslinking is reversed in the immunoprecipitates and the presence of the DNA fragment of interest is monitored by conventional or real-time PCR.

The Maniatis laboratory was one of the first to use this procedure in mammalian cells for their analysis of the interferon- $\beta$ (IFN- $\beta$ ) enhancer (Fig. 2) (Wathelet et al. 1998). Other experiments performed by the Maniatis laboratory had implicated two interferon regulatory factor (IRF) family members, IRF-3 and IRF-7, as relevant activators of the IFN- $\beta$ enhancer, which is induced by viral infection. To test this hypothesis further, the investigators performed ChIP assays with mock- and virus-infected cells. Following formaldehyde crosslinking, extract preparation, and DNA fragmentation, antibodies against various IRF family members were used for immunoprecipitation. PCR analysis of the DNA in the immunoprecipitates revealed that the IFN- $\beta$ enhancer fragment was present following immunoprecipitation with antibodies against IRF-3 and IRF-7, but not with IRF-1 antibodies (Fig. 2). Importantly, the IFN- $\beta$ enhancer fragment was only present in the immunoprecipitates from virus-infected cells and not from mock-infected cells. Immunoprecipitation with antibodies against other DNA-binding proteins (p65, p50, c-Jun, and ATF-2) confirmed that they also interact with the IFN- $\beta$ promoter but not with a control promoter (IFI-56K) (Fig. 2). These results provided strong evidence that IRF-3 and IRF-7 are indeed relevant activators of the IFN- $\beta$ enhancer.

The principal strength of the ChIP assay is that it is the only method currently available to "visualize" directly an in vivo interaction between a specific protein and a control region for an endogenous gene. If compelling data are obtained in well-controlled experiments, investigators can conclude with considerable confidence that a specific protein binds in the vicinity of a DNA element of 


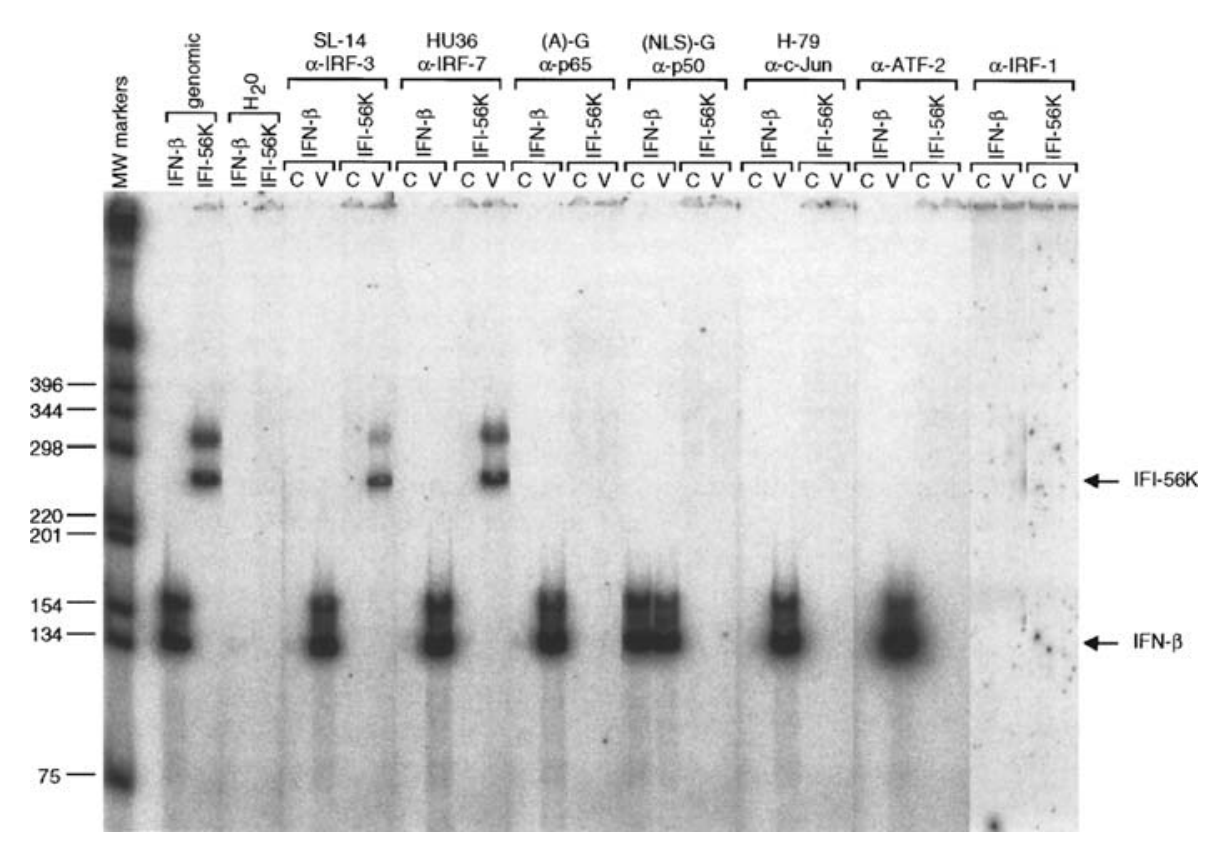

FIGURE 2. Association of specific transcriptional activator proteins with virus-inducible promoters in vivo. HeLa cells were mock (C)- or SV (V)-infected for $6 \mathrm{~h}$, and treated with formaldehyde to crosslink proteins bound to DNA. Crosslinks were purified and immunoprecipitated with the indicated antibodies as described previously (Orlando et al. 1997). After reversing the crosslinking, DNA was amplified using primers for the IFI-56K $(-237 /-219$ and $+12 /$ $+31)$ and IFN- $\beta$ (-129/-117 and -1/-19) promoters by PCR (20 cycles of 1 min each at $94^{\circ} \mathrm{C}, 55^{\circ} \mathrm{C}$, and $\left.72^{\circ} \mathrm{C}\right)$. Molecular mass markers and a control amplification using genomic DNA and water are shown on the left. (Reprinted, with permission, from Wathelet et al. 1998, (c) Cell Press.)

interest in living cells. However, the ChIP assay has a number of limitations. First, it often yields low signals relative to negative controls, leading to results that are not entirely conclusive. Second, because of the assay's limited resolution, it is difficult to identify the precise binding site of the protein; this is particularly relevant if a DNA region contains multiple potential binding sites or entirely lacks recognizable sites. Third, and perhaps most important, ChIP cannot provide evidence that a protein carries out an important function at the control regions to which it binds. Related to this limitation, a positive ChIP signal cannot reveal whether the protein is associated with $95 \%$ of the alleles within a cell population, as would generally be expected for a functional interaction, or only $5 \%$. In fact, numerous studies suggest that transcription factors function at only a subset of the sites with which they interact (see, e.g., Walter et al. 1994; Li and Johnston 2001; Martone et al. 2003; Phuc Le et al. 2005; Beima et al. 2006; Hollenhorst et al. 2007; Dong et al. 2008). In one study performed in S. cerevisiae, the Gal4 protein associated near genes that played no role in cell growth in galactose, and deletion of these Gal4-binding sites had no apparent effect on cell growth (Li and Johnston 2001). In another study performed in mammalian cells, nuclear factor- $\kappa \mathrm{B}(\mathrm{NF}-\kappa \mathrm{B})$ associated with many genes that did not appear to be regulated by this factor (Martone et al. 2003). Interestingly, a more recent study examined the phenotype of mice containing an NF- $\kappa B$ knock in mutation that disrupts a phosphorylation site required for association with the p300/CBP (CREB-binding protein) coactivator. These experiments revealed severe developmental defects caused by the misregulation of developmental regulators that normally do not appear to be NF- $\kappa B$ targets (Dong et al. 2008). Further analysis suggested that these genes were misregulated because NF- $\kappa B$ fortuitously bound to genomic sites close to the genes and promoted their stable silencing when NF- $\mathrm{BB}$ could not properly be converted by phosphorylation from a repressor to an activator (Dong et al. 2008).

It is important to be aware that a positive result in a ChIP assay provides only modest support for the hypothesis that a factor carries out an important function at the interaction site. Thus, other strategies (described below) for testing this hypothesis further must be explored. 
M.F. Carey et al.

\section{Loss-of-Function Studies by Gene Disruption or RNA Interference}

One of the most effective strategies for linking a transcription factor to a target gene is to abolish or knockdown expression of the factor in a cell line or animal, using homologous recombination or RNAi. The loss of function of the DNA-binding protein may result in reduced expression of a candidate target gene, thereby providing evidence that the protein regulates the gene directly. Classical and molecular genetic strategies for disrupting specific genes in model species such as E. coli and $S$. cerevisiae have been available for decades. However, homologous recombination technology for the targeted disruption of specific genes in mice was not developed until the mid- to late-1980s (Folger et al. 1984; Smithies et al. 1985; Thomas and Capecchi 1987; Capecchi 1989, 2005). Disrupting mammalian genes by homologous recombination occasionally is successful in transformed cell lines (see, e.g., Smithies et al. 1985). However, its efficiency in transformed lines is generally lower than its efficiency in mouse embryonic stem (ES) cells. Therefore, gene disruption by homologous recombination usually is accomplished by disrupting one allele in ES cells, followed by generating heterozygous mutant mice, which can be bred to homozygosity. Mice are also preferred over transformed cell lines for gene disruption experiments because a much more meaningful analysis of the mutant phenotype can be performed.

For the conventional disruption of a gene in mice, a targeting construct is prepared containing a drug resistance cassette (usually $n e o^{\mathrm{r}}$ ) flanked by long DNA fragments (homology arms) that are homologous to genomic sequences flanking the region to be altered (Thomas and Capecchi 1987; Capecchi 1989, 2005). The targeting construct is transfected into mouse ES cells, which are then selected for drug resistance and screened for clones that have successfully integrated the targeting construct by homologous recombination, as opposed to nonhomologous integration. Some investigators include a herpes simplex virus thymidine kinase (HSV-TK) gene in the targeting construct outside the homology arms. This gene allows for selection against nonhomologous integration because the HSV-TK cassette will only integrate into the ES cell genome during nonhomologous integration, resulting in cell death when the cells are grown in gancyclovir (Capecchi 2005).

After an ES cell clone is identified in which the targeting construct has integrated by homologous recombination, the clone is expanded and injected into blastocysts, which are then implanted into the uterus. Chimeric offspring are bred until germ-line transmission of the mutant allele is detected. Most investigators use homologous recombination to generate an allele in which a critical region of the gene of interest is flanked by loxP sites, allowing conditional disruption of the gene in specific cell types via selective expression of the Cre recombinase ( $\mathrm{Gu}$ et al. 1994). Additional details about homologous recombination strategies are beyond the scope of this article, but they can be found in the papers cited above.

Gene disruption by homologous recombination remains a preferred strategy for performing lossof-function studies in mammalian cells, as this strategy can result in the complete and specific loss of protein expression. However, because of the considerable time and expense required for gene disruption in mice, investigators have long searched for faster and easier alternatives. Some success was achieved with strategies such as antisense RNA (Branch 1998; Stein 1998). However, the probability of performing a successful loss-of-function experiment with this and other alternatives was generally low, until the discovery of RNAi.

The ability of double-stranded RNAs to promote degradation of a homologous mRNA (Fig. 3) was discovered by Fire et al. (1998). Long double-stranded RNAs promote the degradation of mRNAs in many organisms, including Caenorhabditis elegans and Drosophila melanogaster. However, in mammalian cells, it was necessary to use short double-stranded RNA molecules comparable in size to the products generated by the RNAi processing machinery (generally, 19-26 nucleotides) to avoid provoking an interferon response against the longer molecules (Elbashir et al. 2001a,b). Soon after this key discovery, a number of investigators successfully knocked down mammalian genes by introducing or expressing short interfering RNAs (siRNAs) or short hairpin RNAs (shRNAs) (Barton and Medzhitov 2002; Brummelkamp et al. 2002; Miyagishi and Taira 2002; Paddison et al. 2002; Paul et al. 2002; Sen and Blau 2006). The methods now available range from direct transfection of synthetic siRNAs to 


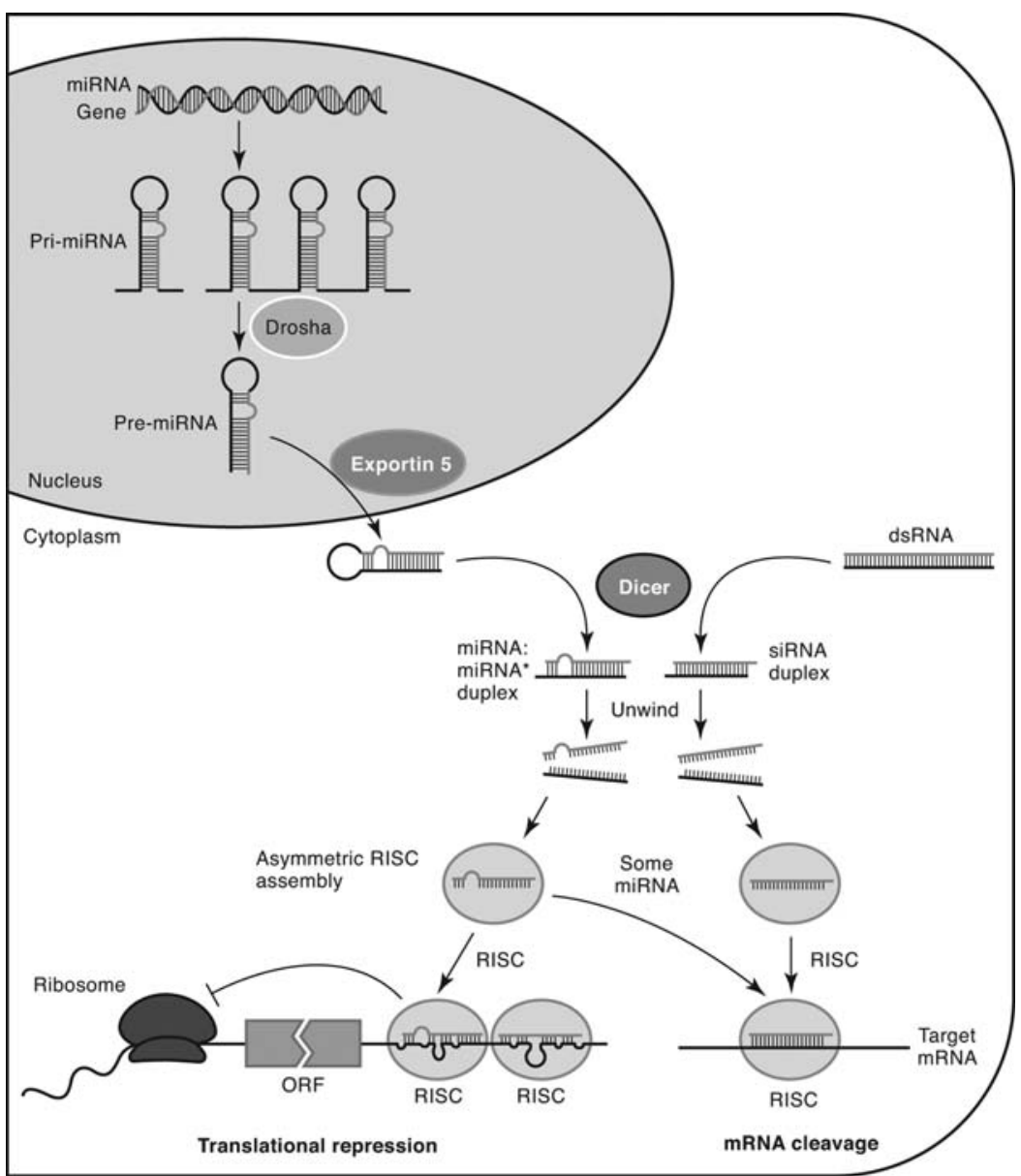

FIGURE 3. RNA interference; processing and mechanisms of action of short interfering RNAs (siRNAs) and microRNAs (miRNAs). ORF, open reading frame; RISC, RNA-induced silencing complex. (Redrawn, with permission of Macmillan Publishing Ltd., from He and Hannon 2004.)

the use of plasmid, retroviral, lentiviral, and adenoviral vectors to introduce genes encoding shRNAs or microRNA precursors under the control of RNA polymerase III or RNA polymerase II promoters. Specific strategies for knocking down the expression of a gene by RNAi are beyond the scope of this article, but they have been the topic of hundreds of articles (for review, see Elbashir et al. 2002; Amarzguioui et al. 2006; Cullen 2006; Pei and Tuschl 2006; Sen and Blau 2006; Snøve and Rossi 2006; Wiznerowicz et al. 2006; Kim and Rossi 2007; Svoboda 2007; Paddison 2008).

RNAi and gene disruption via homologous recombination have proven to be invaluable for assessing the importance of transcription factors for specific biological processes and for the expression of potential target genes. However, a major limitation of all loss-of-function studies is that it can be difficult to determine which genes are regulated directly by the factor and which are indirect targets. In other words, the factor might associate directly with a control region for the gene or it could regulate the gene indirectly by regulating the expression of other genes that then modulate expression of the gene of interest. Even when a loss-of-function result is combined with a positive ChIP signal showing that the factor associates in vivo with a control region for the gene, it is important to interpret the data cautiously: These combined results do not provide definitive evidence that the factor directly regulates the target gene.

When loss-of-function studies are performed by RNAi rather than by gene disruption, additional caution must be exercised because well-documented experimental artifacts are associated with RNAi experiments (Lassus et al. 2002; Cullen 2006; Pei and Tuschl 2006; Snøve and Rossi 2006; Svoboda 
M.F. Carey et al.

2007; Anderson et al. 2008). In particular, siRNAs and shRNAs often are associated with off-target effects, because of their ability to target the degradation of other mRNAs possessing imperfect (but nevertheless sufficient) homology. To help rule out the possibility that a knockdown phenotype is the result of off-target effects, it generally is important to show that two different siRNAs directed against the same mRNA yield similar phenotypes. Alternatively, the knockdown phenotype can be confirmed using a different experimental approach, such as a dominant-negative approach (see below), or the phenotype can be rescued by ectopic expression of an siRNA-resistant version of the gene whose expression has been knocked down. Detailed protocols for designing RNAi experiments and confirming the validity of the results can be found in the papers cited above.

Another major limitation of many loss-of-function experiments is that the disruption or knockdown of a transcription factor can have no effect on expression of a candidate target gene because of redundancy with another related transcription factor or to the compensatory up-regulation of a related factor when the factor of interest is eliminated. The effect of such redundancy on the interpretation of gene disruption results is exemplified by studies of the lymphoid enhancer binding factor 1 (LEF-1) and T-cell factor 1 (TCF-1) proteins implicated in regulation of the T-cell receptor $\alpha$ (TCR$\alpha$ ) enhancer (Clevers and Grosschedl 1996; Okamura et al. 1998). LEF-1 and TCF-1 are highly homologous members of the high-mobility group (HMG)B family of proteins. Both proteins can bind a critical element within the TCR- $\alpha$ enhancer and can transactivate the enhancer in concert with DNA-binding proteins that bind adjacent elements, with LEF-1 transactivation approximately ten times stronger than that of TCF-1. However, disrupting either the LEF-1 or TCF-1 genes had little effect on TCR- $\alpha$ gene transcription (van Genderen et al. 1994; Verbeek et al. 1995). If only one of these proteins were known to exist, it would have been tempting to speculate that the protein was not a relevant activator of the TCR- $\alpha$ enhancer. However, because both proteins had been discovered, the possibility of redundancy was examined by generating mice in which both genes were disrupted. The LEF- $1^{-l-} /$ TCF- $^{-1-}$ mice showed a severe defect in thymocyte development and were deficient for TCR- $\alpha$ gene transcription, strongly suggesting that these proteins are at least partially redundant (Okamura et al. 1998). Thus, although gene disruption and RNAi experiments can provide invaluable information about the relationship between a transcription factor and candidate target genes, a rigorous demonstration that the factor is a direct regulator of the target gene requires additional experimental confirmation.

\section{Abundance of a Protein-DNA Complex In Vitro}

Although ChIP and loss-of-function studies can support the hypothesis that the interaction between a transcription factor and DNA element associated with a target gene is functionally relevant, additional tests of the hypothesis are necessary. These tests can be quite diverse in their level of difficulty and in the extent to which the results support a hypothesis. One of the simplest tests is to evaluate the abundance of an EMSA complex formed when nuclear extracts from appropriate cells are mixed with a radiolabeled probe containing the DNA element of interest. In fact, detecting a prominent protein-DNA complex in an in vitro binding assay often forms the basis for an initial hypothesis that a given protein is responsible for the function of a control element. However, this initial hypothesis requires much more support.

The interleukin-12b (Il12b) promoter analysis offers an example of the limited knowledge provided by the detection of an abundant EMSA complex. To determine which protein is responsible for the function of the $I l 12 b$ promoter element between -88 and -99, an EMSA experiment was performed using extracts from uninduced and induced macrophages (Plevy et al. 1997; Bradley et al. 2003). Several distinct protein-DNA complexes were detected. Specific antibodies added to the binding reactions identified CCAAT enhancer-binding protein $(\mathrm{C} / \mathrm{EBP})-\beta$ in the most abundant complexes. Less abundant complexes contained C/EBP- $\delta$ and C/EBP- $\alpha$. It was therefore hypothesized that $C / E B P-\beta$ is responsible for the function of the $-88 /-99$ element. However, the data do not rule out the possibility that $\mathrm{C} / \mathrm{EBP}-\delta, \mathrm{C} / \mathrm{EBP}-\alpha$, or another binding protein that does not yield a detectable EMSA complex is functionally relevant. C/EBP- $\beta$ could yield the most abundant complex for any 
number of reasons (see Table 1). However, a different protein could be functionally relevant in vivo by, for example, interacting in an optimal physical or functional manner with other proteins that bind the promoter. Alternatively, a less abundant (and therefore undetectable) protein in the cell extract might bind the element with higher affinity in vivo, or a protein not detected with the in vitro EMSA conditions used might bind the control element preferentially in vivo. For the $I l 12 b$ promoter analysis, it is particularly difficult to determine which C/EBP family member is functionally relevant. Although the most abundant EMSA complex contains C/EBP- $\beta, \mathrm{C} / \mathrm{EBP}-\delta$ binds the same sequence, and like $\mathrm{C} /$ EBP- $\beta$, its abundance increases following macrophage activation.

Although the existence of multiprotein families greatly increases the challenge of establishing the functional relevance of a specific protein-DNA interaction, it can also be difficult to identify the relevant protein from among different families. The analysis of the terminal transferase gene (Dntt), which is expressed in immature lymphocytes, provides an example of this issue. DNase I footprinting identified a protein in nuclear extracts from immature lymphocytes that efficiently bound a critical control element in the Dntt promoter, called the $\mathrm{D}^{\prime}$ element (Lo et al. 1991). Following purification and cloning, this protein was found to be Ikaros, suggesting that Ikaros or an Ikaros family member is the relevant activator of Dntt transcription through the D' element (Georgopoulos et al. 1992; Hahm et al. 1994). However, subsequent experiments showed that members of the Ets family of transcription factors can also bind the $\mathrm{D}^{\prime}$ element with considerable affinity, even though these proteins were not easily detected in EMSA or footprinting experiments with crude nuclear extracts (Ernst et al. 1993). Using many of the tests described in this article, the relevance of the Ets- $\mathrm{D}^{\prime}$ interaction for Dntt activation was strongly supported, and the relevance of the Ikaros- $\mathrm{D}^{\prime}$ interaction was not (Ernst et al. 1996). It remains unknown why Ikaros is the predominant $\mathrm{D}^{\prime}$-binding protein in nuclear extracts from Dntt-expressing cells, despite several lines of evidence suggesting that it is not a relevant activator of transcription through this element.

\section{Relative Expression Patterns of the DNA-Binding Protein and Target Gene}

Another straightforward test of the hypothesis that a protein-DNA interaction is functionally relevant is to compare the expression patterns of the binding protein and its putative target gene. This test can be performed with transformed cell lines and primary cells by first quantifying steady-state mRNA levels or nascent transcripts from the putative target gene. The expression pattern of the proposed regulatory protein can then be monitored by measuring steady-state protein levels using immunoblot, immunoprecipitation, immunofluorescence, flow cytometry, or a biochemical assay.

The methods that are available for monitoring each DNA-binding protein and target gene vary. However, the preferred comparison would involve assays that are most meaningful for demonstrating a relationship between the active DNA-binding protein and the putative target gene; namely, a biochemical assay to quantify the DNA-binding activity (or capacity for transcriptional activation) of the protein, and a nuclear run-on assay or real-time RT-PCR assay to monitor nascent transcription of the target gene. DNA-binding activity can be monitored by EMSA or DNase I footprinting. For some transcription factors that require a specific posttranslational modification for their ability to stimulate transcription, it may be useful to perform western blots with antibodies specific for the modified protein, to gain further knowledge of which cells contain active protein. As an alternative to the nuclear run-on assay, nascent precursor (unspliced) transcripts can be monitored by RT-PCR using primers that span an exon-intron junction (see Lipston and Baserga 1989; Reddy et al. 1994; Bradley et al. 2003). The reason for monitoring nascent transcripts rather than mature mRNA is that nascent transcript levels often provide a more accurate reflection of transcription level, because mRNA abundance is thought to be more strongly influenced by changes in stability. Of course, analysis of mRNA abundance by RT-PCR should be sufficient for monitoring target gene expression in many cases. The information gained by carefully comparing the expression patterns of the DNAbinding protein and target gene can either support or help to rule out a hypothesis. If the DNAbinding protein of interest is present in all of the cell types that express the target gene, the results would support the hypothesis that the protein is a relevant activator of the target. If, on the other hand, 
M.F. Carey et al.

cells are identified that express the target gene but not the putative activator, the hypothesis would be weakened. The hypothesis would not be negated, however, because some genes are activated by different sets of factors in different cell types (see, e.g., Lauring and Schlissel 1999).

It is important to note that a target gene is rarely, if ever, expressed in all of the cell types that express a relevant transcriptional activator. More likely, it is expressed in only a subset of these cells. According to basic combinatorial principles of gene regulation, a given DNA-binding protein contributes to the transcription of many genes with varying expression patterns by acting in conjunction with several other transcription factors, each possessing its own unique expression pattern. In addition, as mentioned above, numerous transcription factors are regulated by posttranscriptional mechanisms, allowing them to be present in an inactive state (or in an inappropriate subcellular compartment) in cells that do not express relevant target genes (e.g., NF- $\kappa \mathrm{B}$, nuclear factor of activated T cells [NFAT], and nuclear hormone receptors). Although this latter issue can be addressed in part by using an assay that monitors the abundance of active transcription factor (see above), a perfect correlation between transcription factor abundance and target gene is almost never observed. One additional limitation is that correlated expression of activator and target gene does not provide a direct functional link between the two. The correlation could be fortuitous or the activator might regulate the target gene indirectly by regulating one of the gene's direct regulators.

For genes that are inducible in a cell line or tissue, the basic expression pattern analysis can be enhanced by comparing the kinetics of transcription factor and target gene induction. The cells can be treated with an appropriate inducing agent and the time course of induction of the DNA-binding activity in nuclear extracts can be compared with the time course of induction of the target gene (or a chromosomally integrated reporter gene). If the induction kinetics are similar or if the DNA-binding activity is induced slightly earlier than the target gene, then the protein could indeed regulate the gene. For some classes of transcription factors, such as nuclear hormone receptors, kinetic experiments can provide strong evidence that a protein-DNA interaction is relevant.

A caveat to interpreting kinetic experiments is that the precise concentration of DNA-binding protein that needs to be present for a target gene to be activated is usually unknown. For example, if a target gene were activated when the DNA-binding protein reaches a concentration that is only $1 \%$ of its maximum, the results would suggest initially that target gene induction is independent of the activator. In some instances, a high threshold concentration of a critical DNA-binding protein must be present for target gene activation (Fiering et al. 1990). If the threshold concentration of a protein is indeed high, a kinetic analysis can be informative. However, in the absence of information about the threshold concentration, it is difficult to evaluate experiments that attempt to correlate the kinetics of induction of a transcription factor and target gene.

\section{Correlation between Nucleotides Required for Protein Binding and Those} Required for Activity of the Control Element

Another fundamental test of the functional relevance of a protein-DNA interaction involves comparing the nucleotides required for the function of the control element and the nucleotides required for binding the putative transcription factor. This is an extremely powerful and underutilized method that can provide relatively strong evidence that a particular DNA-binding protein, or at least a member of a particular family of such proteins, is responsible for the activity of the control element.

The Dntt promoter analysis provides an example of this strategy. As mentioned previously, the $\mathrm{D}^{\prime}$ element can interact with both Ikaros and Ets proteins. Ikaros was the predominant $\mathrm{D}^{\prime}$-binding protein observed in extracts from Dntt-expressing cells, suggesting that it might be the functional activator. The expression patterns of Ikaros and Ets proteins could not distinguish which protein was the functional activator because proteins of both families were expressed in all Dntt-expressing cells examined. A detailed mutant analysis of the $\mathrm{D}^{\prime}$ element proved to be useful for identifying the relevant protein family (Ernst et al. 1996). A series of single- and double-base substitutions in the Dntt (TdT) $\mathrm{D}^{\prime}$ element were constructed and tested for their effect on promoter function in transient and stable transfections and for their effect on the Ikaros and Ets binding. The results (Table 2) revealed that the 
TABLE 2. Effect of substitution mutations on promoter function and protein binding to the Dntt $\mathrm{D}^{\prime}$ element

\begin{tabular}{|c|c|c|c|c|c|c|c|c|c|c|c|c|c|c|}
\hline $\mathrm{D}^{\prime}$ Sequence $^{\mathrm{a}}$ & & & & & & & & & & & & $\begin{array}{l}\text { Promoter } \\
\text { function }\end{array}$ & $\begin{array}{c}\text { Ets } \\
\text { binding }\end{array}$ & $\begin{array}{c}\text { Ikaros } \\
\text { binding }\end{array}$ \\
\hline Wild type & G & $\mathrm{C}$ & A & G & G & A & A & G & $\mathrm{T}$ & $\mathrm{T}$ & G & + & + & + \\
\hline m83 & G & A & A & G & G & A & A & G & $\mathrm{T}$ & $\mathrm{T}$ & G & $+/-$ & $+/-$ & + \\
\hline m84 & G & $\overline{\mathrm{C}}$ & $\underline{C}$ & G & G & A & A & G & $\mathrm{T}$ & $\mathrm{T}$ & G & +++ & ++ & - \\
\hline m85 & G & $\mathrm{C}$ & $\overline{\mathrm{A}}$ & $\underline{T}$ & $\underline{T}$ & A & A & G & $\mathrm{T}$ & $\mathrm{T}$ & G & - & - & - \\
\hline m86 & G & C & A & $\dot{\bar{G}}$ & $\overline{\mathrm{G}}$ & C & C & G & $\mathrm{T}$ & $\mathrm{T}$ & G & - & - & - \\
\hline m87 & G & $\mathrm{C}$ & A & G & G & $\bar{A}$ & $\overline{\mathrm{A}}$ & $\underline{T}$ & $\mathrm{~T}$ & $\mathrm{~T}$ & G & - & - & + \\
\hline m88 & $\underline{A}$ & $\mathrm{C}$ & $\underline{\mathrm{C}}$ & G & G & A & A & $\bar{G}$ & $\mathrm{~T}$ & $\underline{A}$ & G & +++ & ++ & - \\
\hline
\end{tabular}

${ }^{\text {a }}$ Nucleotide substitutions are underlined.

nucleotides required for Ikaros binding were significantly different from the nucleotides required for promoter activity in both transfection assays. Two different mutations enhanced promoter activity while abolishing Ikaros binding, and another mutation abolished promoter activity without affecting Ikaros binding. In contrast, the nucleotides required for promoter activity matched precisely the nucleotides required for the binding of various proteins of the Ets family. The results support the hypothesis that an Ets family protein is a functional activator of Dntt transcription.

This strategy, however, has significant limitations. In particular, although it can address the relevance of different families of proteins, it usually provides little distinction between members of the same family. This problem is particularly severe for families such as the Ets family, in which a large number of family members show very similar or identical DNA-binding specificities, with several family members expressed in most cell types (Hollenhorst et al. 2004, 2007). In addition, the assays used to monitor the effect of mutations (e.g., transfection assays) are artificial. In the example discussed above, the nucleotide requirements for activity of the $\mathrm{D}^{\prime}$ element in transfection assays likely reflect the requirements for $\mathrm{D}^{\prime}$ activity in the endogenous gene. Nevertheless, the high plasmid copy number used for the transfection assay and the removal of the control region from its natural context could alter the outcome of the analysis. A final limitation is that careful mutant studies are much more difficult to evaluate if the function of the element depends on the simultaneous binding of two or more proteins. In such cases, it can be very difficult to correlate the nucleotides required for activity with the nucleotides required for binding an individual protein. Despite these limitations, this strategy often provides useful information.

Transactivation of a Reporter Gene or Endogenous Gene by Overexpression of a DNA-Binding Protein

The ability of an overexpressed or ectopically expressed protein to transactivate a reporter gene regulated by the control region of interest, or to transactivate an endogenous gene, can provide support for the functional relevance of a protein-DNA interaction. However, these experiments are difficult to interpret when the DNA-binding protein is expressed at a higher concentration than is found in a normal cell. The presence of multiple copies of a reporter plasmid in a transfected cell can lead to similar interpretation problems.

One common approach begins with the insertion of a cDNA encoding the DNA-binding protein into a vector that drives expression following introduction into cultured cells (Fig. 4). For mammalian cells, common expression vectors contain a strong viral promoter/enhancer, such as that derived from cytomegalovirus (e.g., pcDNA3.1 [Invitrogen]). Cultured cells are then cotransfected with this expression plasmid and a reporter plasmid regulated by the control region of interest; the reporter assay is used to monitor the effect of the overexpressed protein on the activity of the control region. If overexpression results in activation of the control region, the requirement for the protein's binding site can be assessed by repeating the experiment with a reporter plasmid containing a binding site mutant. In this experiment, transactivation should not be observed. 
M.F. Carey et al.

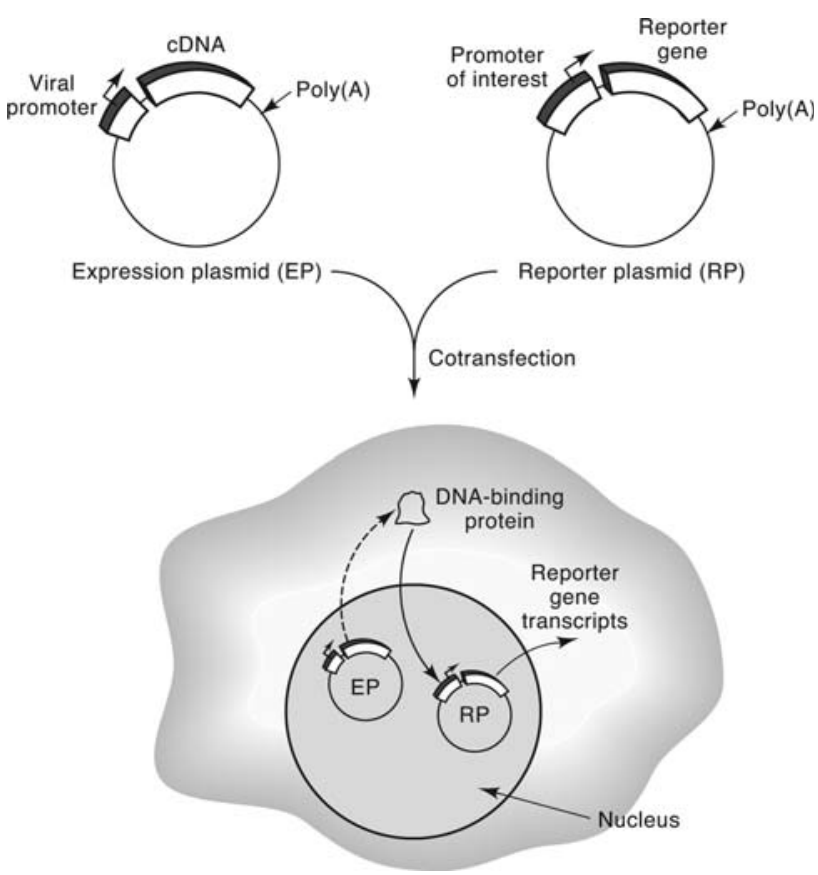

FIGURE 4. Transactivation of reporter gene expression by ectopic overexpression of a transcription factor. (Reprinted, with permission, from Lodish et al. 1996, (c) 1986, 1990, 1995, 2000, 2008 by W.H. Freeman and Company.)

A positive result with this type of experiment strongly suggests that the DNA-binding protein can activate the control region when both the DNA-binding protein and control region are over-produced. However, it provides little evidence that the protein, when expressed at physiological concentrations, can regulate the two copies of the endogenous target gene present in diploid cells. Current models suggest that genes are regulated by multiple protein-DNA and protein-protein interactions. By substantially increasing the concentration of a protein that is not normally involved in regulating a gene, aberrant protein-protein and/or protein-DNA interactions might occur that are sufficient for the gene to be activated or repressed. Overexpression of the reporter plasmid containing the control region of interest can also enhance protein-DNA interactions that do not normally occur.

An example of this approach is provided by the $I l 12 b$ promoter analysis (Plevy et al. 1997). To test the hypothesis that C/EBP- $\beta$ is a relevant activator through the $-88 /-99$ element, uninduced macrophages were cotransfected with a C/EBP- $\beta$ expression plasmid and an $I l 12 b$ promoter-reporter plasmid. Overexpressed C/EBP- $\beta$ enhanced promoter activity in uninduced cells to a level comparable to that observed in induced cells in the absence of overexpression. Mutation of the C/EBP- $\beta$-binding site abolished the transactivation. These results appear to suggest that C/EBP- $\beta$ is a relevant activator of the Il12b promoter. However, they merely show that the promoter can be activated when C/EBP- $\beta$ and the $I l 12 b$ promoter-reporter plasmid are present at unusually high concentrations. The results provide no significant evidence that C/EBP- $\beta$, when present at physiological concentrations, is a relevant activator of the endogenous $I l 12 b$ gene.

These same issues must be considered when an overexpressed transcription factor is found to transactivate an endogenous gene. However, in this instance, a positive result might provide a modest level of support for the hypothesis being tested. First, if the overexpressed DNA-binding protein can transactivate the endogenous gene in a cell type that does not normally express the gene, it must be capable of carrying out protein-DNA and protein-protein interactions that are of sufficient specificity and affinity to overcome chromatin barriers, etc. Second, because only two copies of the endogenous gene exist in a diploid cell, strong activation by a protein that is not physiologically relevant seems to be less likely; to achieve significant levels of transcription from an endogenous gene, highly specific interactions with other proteins may be required. 
One potential solution to the overexpression problem is to express the protein ectopically at a concentration comparable to that found in normal cells. This might be possible by stably expressing the protein. Individual cell clones can then be isolated and tested for protein expression levels. Clones that express the protein at a level comparable to that found in a cell line that expresses it naturally can be used for further analysis of target gene transcription. Although this might provide useful information, ectopic expression of a single DNA-binding protein at a normal concentration is unlikely to be sufficient to activate a target gene, unless it is truly the only regulator of that gene missing from the cells being used. If other tissue-specific proteins are needed, the gene will not be efficiently activated.

Another experiment that can address concerns about protein overexpression is a comparison of the activities of several members of a transcription factor family when each is overexpressed to a similar extent. If only one family member transactivates a control region, it must bind the control element with an unusually high affinity or it must be capable of carrying out specific interactions with other proteins needed for the control region to function.

\section{Cooperative Binding and Synergistic Function of Proteins Bound} to Adjacent Control Elements

Support for the functional relevance of a protein-DNA interaction can sometimes be provided by the selective ability of the protein to bind cooperatively with other proteins that interact with the control region. Support can also be provided by the selective ability of the protein to synergize functionally with other proteins.

Specific protein interactions at the immunoglobulin $(\operatorname{Ig}) \times 3^{\prime}$ enhancer provide one example of cooperative binding as evidence of a functional protein-DNA interaction (Pongubala et al. 1992; Eisenbeis et al. 1995). Two of the critical elements within this enhancer are immediately adjacent to each other and appear to act in synergy. EMSA experiments performed with nuclear extracts and a radiolabeled probe spanning the two elements yielded a complex containing proteins bound to both sites (Fig. 5, lane 1) (Pongubala et al. 1992). DNA binding by the two proteins was highly cooperative, as mutation of either site strongly reduced protein binding to the probe (Fig. 5, lanes 4-8). One protein within the complex was found to be an Ets protein named PU.1, and the other was identified as IRF-4, also known as Pip (Eisenbeis et al. 1995). The detection of a stable complex containing proteins bound cooperatively to two functionally important sites provides strong evidence that these proteins (and not other members of the Ets and IRF families) are the relevant regulators of the Igא

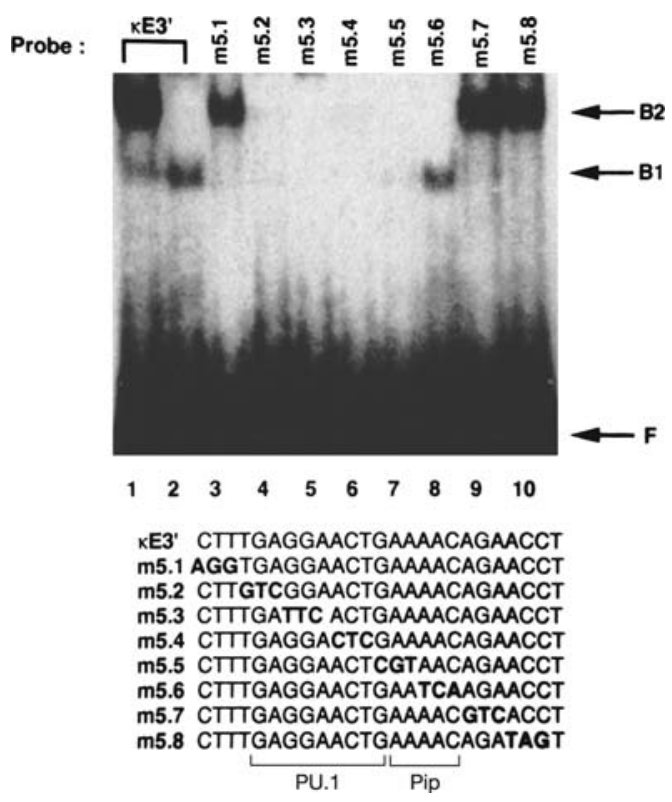

FIGURE 5. Highly cooperative binding of PU.1 and IRF-4 (Pip) to the Igא $3^{\prime}$ enhancer. EMSA experiments were performed with radiolabeled oligonucleotides containing the wild-type or mutant enhancer sequences shown at the bottom. (Lanes 1 and 3-10) Binding reactions were performed with nuclear extracts from the S194 cell line. The binding reaction in lane 2 contains in vitro-translated PU.1. (Band B2) PU.1 and IRF-4 bound cooperatively to the probe; (Band B1) PU.1 alone; (Band F) corresponds to free probe. The locations of the PU.1 and IRF-4 (Pip)-binding sites are depicted at the bottom. (Adapted, with permission, from Pongubala et al. 1992, (CAmerican Society for Microbiology.) 
enhancer. As discussed earlier, the detection of an EMSA complex with an isolated control element provides relatively weak evidence that the protein is functionally relevant because the criteria for the in vitro detection of a protein-DNA interaction are very different from the criteria for a relevant in vivo interaction. Nevertheless, if an EMSA complex observed with a crude extract contains proteins bound cooperatively to two sites that are functionally synergistic in vivo, the probability that the proteins within the complex are functionally relevant increases substantially.

A key limitation of this assay is that strong, cooperative binding and functional synergy are observed with only a small subset of protein-DNA interactions. If cooperative binding to the control region is not observed in vitro, this strategy will not be useful. The PU.1/IRF-4 example is particularly powerful because the cooperatively bound proteins are easily detected in EMSA experiments using crude nuclear extracts. If cooperative binding were observed only when two recombinant proteins were added to an EMSA experiment, the results would provide much weaker support for the hypothesis. In this case, a demonstration of the selectivity of the cooperative binding would be needed, by comparing various Ets and IRF family members.

The IFN- $\beta$ enhanceosome provides a second prominent example of cooperative binding and synergistic activation that highlights both the strengths and limitations of this approach (Thanos and Maniatis 1995a,b; Kim and Maniatis, 1997; Wathelet et al. 1998; Panne et al. 2007). Early studies found that IRF-1 interacts with a functionally important enhancer element and binds cooperatively to the enhancer with other transcription factors, including ATF-2/c-Jun and NF- $\mathrm{KB}$ (Thanos and Maniatis 1995b; Kim and Maniatis 1997). IRF-1 also can transactivate the enhancer in synergy with those factors. These data suggested that IRF- 1 is a relevant activator of IFN- $\beta$ transcription. However, a later study by Wathelet et al. (1998) using ChIP (discussed above) argued against that hypothesis. In that study, a protein complex was identified that interacted with the IRF recognition element following induction of IFN- $\beta$ transcription. However, the inducible complex did not contain IRF-1, but rather two other IRF family members, IRF-3 and IRF-7. Additional experiments confirmed that IRF-3 and IRF-7, but not IRF-1, contribute to the activation of IFN- $\beta$ transcription in vivo. In particular, a single-base-pair substitution in the enhancer abolished IRF-1 binding but had no effect on IRF-3/IRF7 binding or on enhancer activity. Thus, despite the initial evidence that IRF- 1 can bind cooperatively to the enhancer with other relevant factors, and synergistically activate the enhancer in concert with those factors, it appears to be irrelevant for enhancer activity or IFN- $\beta$ transcription.

The initial IRF-1 studies were misleading primarily because recombinant proteins were used to show cooperative binding and synergistic activation. This contrasts with the PU.1/IRF-4 studies, in which the cooperative interactions were observed first in crude nuclear extracts from cells that express the Igא gene; recombinant proteins and overexpressed proteins were not needed. When cooperative interactions were finally observed with the IFN- $\beta$ enhancer in crude nuclear extracts from induced cells (in the absence of protein overexpression), the complex was found to contain IRF-3 and IRF-7 instead of IRF-1.

\section{Comparison of Genomic and In Vitro Footprinting Patterns}

The ChIP assay is useful for assessing the possibility that a factor binds a specific control region in vivo that has been hypothesized to interact with the factor. However, ChIP assays do not provide quantitative information about the fraction of alleles within a cell population that are associated with the factor of interest. This can be problematic if two different factors are believed to interact with the same element and both give positive results in ChIP experiments. In such a scenario, it is possible that one of these factors might associate fortuitously, and with no functional relevance, with a very small fraction of alleles. Alternatively, a factor could yield a positive ChIP signal because it interacts relatively nonspecifically in the vicinity of the control region, without specific recognition of the DNA element of interest.

One way to gain insight into the identity of the DNA-binding protein that binds most efficiently to a site in a cell population is to compare the genomic footprinting pattern observed with cells that actively express the target gene to the pattern observed in vitro with a known DNA-binding protein. This comparison can be performed using genomic footprinting methods, including DNase I 
footprinting or dimethylsulfate (DMS) protection. If the footprint observed in vitro matches the pattern observed in vivo, the protein analyzed in vitro might actually be the protein that is efficiently bound to the endogenous gene when it is active, suggesting that it is the relevant activator. If DNase I footprinting is used for the comparison, it usually will be necessary to use ligation-mediated PCR (LM-PCR) technology for both the in vitro and genomic footprinting procedures, because it is difficult to compare footprinting results obtained by LM-PCR with those obtained using radiolabeled probes. In contrast, if DMS footprinting is used, the results obtained by LM-PCR in vivo can be compared directly with the results obtained in vitro using a radiolabeled probe.

This strategy was used during the analysis of the lymphocyte-specific Rag2 promoter (Lauring and Schlissel 1999). In vitro EMSA studies showed that the B-cell activator, Pax5, could interact with an important control element. These results suggested that Pax5 is an important activator of Rag2 transcription in B cells. An in vivo interaction at the element was observed by DMS genomic footprinting, but in vivo footprinting results did not reveal the identity of an interacting protein. To provide evidence that the protein bound to the site in vivo was Pax5, a DMS protection analysis was performed in vitro using recombinant protein. The in vivo and in vitro interaction patterns were identical, suggesting that Pax5 is indeed the protein that occupies the endogenous element in B cells.

The primary limitation of this strategy is that the results do not usually distinguish between the various members of a protein family; most family members lead to a similar footprint. Furthermore, some DNA-binding proteins do not yield footprinting patterns that are sufficiently unique, making it difficult to determine whether the protein bound to the endogenous locus in vivo is related to the known protein being tested in vitro. Nevertheless, if clear genomic and in vitro footprints with characteristic properties are obtained, this comparison can provide support for the role of a particular protein family in the function of a defined control element.

\section{Relative Affinity of a Protein-DNA Interaction}

One property of a protein-DNA interaction that can support its relevance is its affinity, relative to the affinities of other protein-DNA interactions that can occur at the same site. To our knowledge, the relationship between affinity and functional relevance of a transcription factor has not been examined carefully and systematically, although, in model systems, the affinity of a transcription factor for its target site is proportional to activation (see, e.g., Mauxion et al. 1991; Lehman et al. 1998). In some cases (e.g., the PU.1/IRF-4 example described previously), low-affinity interactions by the individual DNA-binding proteins are preferred so that the activity of the composite element remains dependent on cooperative binding by two or more proteins. Nevertheless, it seems possible that, in many instances, the protein that functionally interacts with a control element will bind with an unusually high affinity, relative to the affinities of irrelevant proteins capable of binding the same site.

Affinity may be a particularly useful criterion for determining which member of a multiprotein family is most likely to carry out a functional interaction with an element. Although various members of a multiprotein family may recognize very similar sequences, they often have subtle sequence preferences. These preferences could play a major role in determining which factor acts on a given control element. If this hypothesis is correct, a careful comparison of binding affinities of the members of a multiprotein family for a site might be useful.

Several methods are available to compare relative affinities of a variety of proteins for a given site. One can obtain pure recombinant proteins and perform careful equilibrium dissociation constant measurements. This method provides valuable information, but it has two disadvantages. First, it is difficult to prepare and accurately quantify recombinant forms of all the proteins that should be tested, particularly when working with a large multiprotein family. More importantly, the affinity of a recombinant protein for a DNA sequence can be significantly different from that of the native protein. One reason for this is that protein-DNA interaction affinities can be altered by posttranslational modifications or by interactions with other proteins. In particular, a growing number of proteins are being found to possess autoinhibitory domains that reduce their affinities for DNA unless appropriately modified (see, e.g., Jonsen et al. 1996; Lee et al. 2005; Pufall et al. 2005). 
A more informative experiment would be to compare relative affinities in a cell extract, in which the proteins are more likely to exist in their native state. If most of the proteins of interest within an extract are sufficiently concentrated to permit their detection in a basic EMSA, an approximate comparison of their affinities for a site can be obtained. One approach is to determine the susceptibility of each protein-DNA complex to nonspecific competitor DNA, salt, or detergent by titrating each into the binding reactions. Higher-affinity interactions are likely to be more resistant to these reagents, particularly if one is comparing members of a family. Unfortunately, this approach can compare only those proteins that are sufficiently concentrated to be detected in a basic EMSA experiment. Proteins that are of relatively low abundance, or whose binding properties are incompatible with the EMSA conditions being used, cannot be tested.

An alternative approach was performed with the Dntt D' element discussed above (Fig. 6) (Ernst et al. 1996). The goal was to determine which Ets protein within an extract from a Dntt-expressing cell line bound to the $\mathrm{D}^{\prime}$ element with highest affinity (i.e., to identify a candidate for the functional activator of Dntt transcription). Several known, and perhaps other novel, Ets proteins are present in Dntt-expressing cells, but only a few EMSA complexes containing Ets proteins can be detected using nuclear extracts. To avoid bias toward known proteins or proteins that could be detected by EMSA using crude extracts, sequence-specific DNA affinity chromatography was used. The highest-affinity proteins would be expected to elute from an affinity column with the highest salt concentration. Indeed, following affinity chromatography, a single abundant EMSA complex was observed in the high-salt eluates, with all other EMSA complexes more abundant in the lower-salt eluates. A silverstained protein gel identified the protein responsible for the complex (Fig. 6, complex Y), and peptide sequencing revealed that the protein was an Ets protein called Elf-1. Immunoblots of column fractions confirmed that Elf-1 eluted at higher salt concentrations than several other Ets family members. Subsequent experiments provided additional support for Elf-1 as a functional activator of Dntt transcription through the $\mathrm{D}^{\prime}$ element. However, the hypothesis remains unproven. Thus, it is not yet known from this study or studies performed in other laboratories whether affinity within a large family of closely related proteins is valid for assessing functional relevance.

The affinity chromatography approach possesses several advantages over the other affinity strategies mentioned above. First, the native proteins in the crude extract are more likely to retain posttranslational modifications present in the intact cells. Second, this method is not biased toward the most abundant proteins or previously described proteins. In fact, this strategy should result in the purification of any protein of reasonable abundance that binds the site with high affinity. Finally, if the high-affinity binding protein is novel, it can be identified by mass spectrometry.
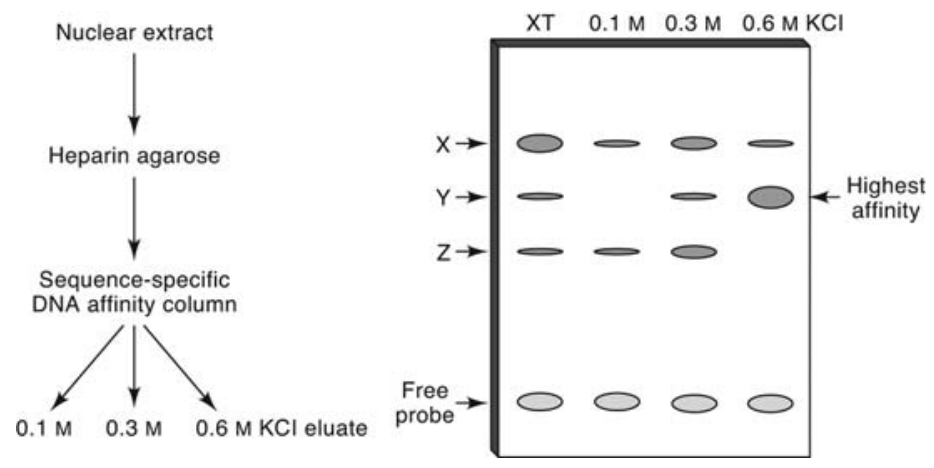

FIGURE 6. Comparison of protein-DNA interaction affinities in crude nuclear extracts by sequence-specific DNA affinity chromatography. Nuclear extracts from the murine T-cell line RLm11 were fractionated initially by heparinagarose to remove nucleases. Sequence-specific DNA affinity chromatography was then performed using a resin with covalently linked oligonucleotides containing the D' element from the Dntt promoter. The sample was applied to the column in a buffer containing $0.1 \mathrm{M} \mathrm{KCl}$. Proteins were then eluted with 0.3 and $0.6 \mathrm{M} \mathrm{KCl}$. Right, an idealized EMSA result is depicted; three protein-DNA complexes were detected when the extract was used (lane 1), but only one (complex Y) was retained on the column preferentially until the $0.6 \mathrm{~m} \mathrm{KCl}$ elution (lane 4). 
A notable limitation of the affinity chromatography method is that the posttranslational modifications present in the intact cell might not be retained in the extract. Furthermore, the use of affinity chromatography as a measure of relative affinities can be somewhat inaccurate if the different proteins that bind a site rely to different extents on electrostatic interactions between the DNA-binding domain and DNA. If the electrostatic interactions are substantially different, salt elution from an affinity column will not provide an accurate assessment of relative affinities.

\section{Dominant-Negative Mutants}

By definition, a dominant-negative mutant is a protein variant that, when expressed in a cell containing the wild-type protein, disrupts the functions of that protein. Disruption usually occurs because the mutant retains some, but not all, of the wild-type protein's activities. This allows it to compete, albeit nonproductively, for an important target or substrate of the wild-type protein. Dominantnegative mutants of a DNA-binding protein can sometimes provide information about the functional importance of a protein-DNA interaction. However, the information provided by these experiments is limited, and the type of dominant-negative mutant used has a notable impact on the interpretation of the data.

A common method for performing dominant-negative studies is to cotransfect cells with a reporter plasmid containing a standard reporter gene regulated by the control region of interest and an expression plasmid for a dominant-negative version of the DNA-binding protein (Fig. 7).

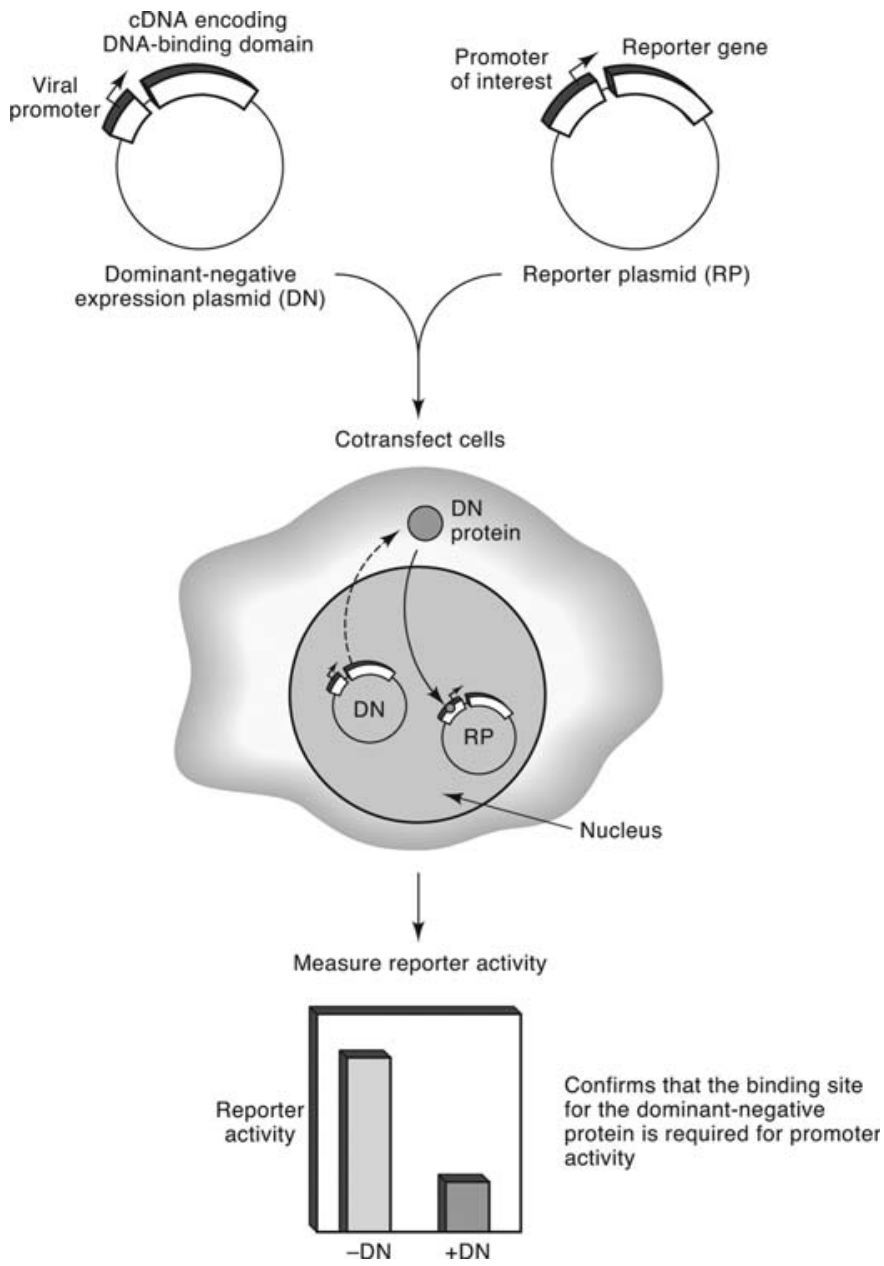

FIGURE 7. Inhibition of reporter activity by a dominant-negative version of a transcription factor that retains its DNAbinding domain. 
The dominant-negative protein is often designed to retain the capacity to bind DNA but not to perform transcriptional activation functions. In other words, the protein contains its DNA-binding domain but lacks its transcriptional activation domains. The mutant protein is expected to compete with the endogenous wild-type protein, thereby preventing the wild-type protein from activating reporter gene transcription (Fig. 7). Inhibition with this type of dominant-negative protein is often used to provide evidence that the wild-type protein functionally activates the control region fused to the reporter.

This approach was used by Plevy et al. (1997) to support the hypothesis that C/EBP- $\beta$ is a relevant activator of the $I l 12 b$ promoter in lipopolysaccharide (LPS)-activated macrophages. Increasing concentrations of an expression plasmid for a dominant-negative form of C/EBP- $\beta$ called LIP (Descombes and Schibler 1991) were cotransfected into the macrophages along with an Il12b promoter-reporter plasmid. LIP contains the basic leucine zipper (bZIP) DNA-binding and dimerization domains of C/EBP- $\beta$, but it lacks its transcriptional activation domains. The cells were then activated with lipopolysaccharide (LPS), and the effect of LIP on Il12b promoter activity was monitored using the reporter assay. The results showed that promoter activity was suppressed by LIP. Control experiments showed that LIP expression had no effect on reporter plasmids containing promoters lacking C/EBP-binding sites.

Dominant-negative experiments of this type can support a hypothesis regarding the functional relevance of a DNA-binding protein such as C/EBP-B. However, a careful consideration of the experiment reveals that the results merely confirm that the DNA-binding domain, when overexpressed, is capable of binding to the important control element, where it blocks activation by the functional activator. Regardless of the identity of the functional activator, the overexpressed dominant-negative mutant could block the important protein-DNA interaction, simply by occupying the binding site. Thus, the results provide two relatively modest pieces of information: (1) The control element to which the dominant-negative protein binds is important for the function of the control region, a result already established by the promoter mutant analysis, and (2) the DNA-binding domain within the dominant-negative protein is capable of binding to that control element in vivo when overexpressed.

An alternative experiment is to test the effect of the same dominant-negative mutant on expression of the endogenous gene. This provides an opportunity to confirm that a control element found to be important in an artificial transfection assay is also an important regulator endogenously. However, this experiment suffers from most of the above limitations and from two additional caveats. First, it is possible that the dominant-negative protein inhibits transcription from the endogenous target gene indirectly by altering expression of other genes within the cell. For example, the dominant-negative protein could inhibit expression of genes needed for survival, leading to toxicity that indirectly inhibits transcription from the target gene. (The possibility of indirect effects must also be considered when analyzing the effect of a dominant-negative protein on a transfected reporter plasmid, but this can be addressed, at least in part, by testing a mutant reporter.) Second, analyzing an endogenous target gene is technically more difficult than analyzing a transiently cotransfected dominant-negative mutant and reporter plasmid. In the cotransfection assay, virtually every cell that takes up the reporter plasmid takes up the dominant-negative expression plasmid. Thus, the entire cell population can be analyzed for the effect of the dominant-negative protein. In contrast, to monitor the effect on endogenous gene transcription, one must recognize that only a fraction of the cells will be transfected and express the dominant-negative protein. Because the majority of cells will not be transfected, it can be difficult to observe the effect of the dominant-negative protein on target gene expression.

There are, however, several fairly straightforward solutions to these additional difficulties. First, the dominant-negative protein can be expressed from a high-titer retroviral vector that can infect all of the cells, perhaps leading to a measurable effect on transcription of the putative target gene. Second, the dominant-negative protein can be expressed in the cells by stable transfection. Preferably, the dominant-negative protein should be under the control of an inducible promoter, so that any toxicity of the protein is not manifested during the selection process. Third, the cells that are transiently transfected with the dominant-negative expression plasmid can be separated from the untransfected cells by flow cytometry or a related immunologic method. 


\section{In Vitro Transcription Strategies}

In vitro transcription experiments can support the relevance of a protein-DNA interaction. The basic approach begins with the development of an in vitro transcription assay for the control region, which can often be quite challenging. Nucleosome reconstitution can aid in the assay's development. To determine whether the DNA element of interest contributes to in vitro activity, mutations in the element can be tested. If the assay is dependent on the DNA element, it may be possible to use it to assess the relevance of a particular DNA-binding protein for the element's function. As a starting point, monoclonal or polyclonal antibodies directed against the candidate protein can be added to in vitro reactions to determine whether they block the function of the control element (Fig. 8A). Concentrated, affinity-purified antibodies may be needed because it can be difficult to add sufficient antibody to neutralize the protein. To determine whether sufficient antibody has been added, its effect on an EMSA complex can be monitored. Control experiments should also be performed to determine whether the antibody affects transcription from an unrelated promoter that is independent of the DNA-binding protein. Additional controls are also needed, including reactions monitoring the effect of an unrelated antibody prepared by a similar method. If antibody addition does not inhibit transcriptional activity, the candidate binding protein might not be essential for the activity of the control element. Alternatively, the antibody might not bind to an essential protein epitope or be sufficiently concentrated to neutralize all of the protein molecules within the extract.

An alternative, and potentially more successful, strategy is to deplete the protein from the extract by immunoprecipitation or immunoaffinity chromatography, or by sequence-specific DNA affinity chromatography (Fig. 8B). The immunoprecipitation and immunoaffinity methods should allow the efficient depletion of a protein from an extract, unless the critical epitope of the protein is blocked by tight association with other proteins. DNA affinity chromatography results in the depletion of all proteins that bind the element of interest, providing little insight into the identity of the protein that functionally interacts with the element. However, that insight can be provided by the subsequent addition of a recombinant or pure form of the putative regulator. If efficient transcription is restored, the results support the hypothesis that the protein is a relevant regulator of the gene. 


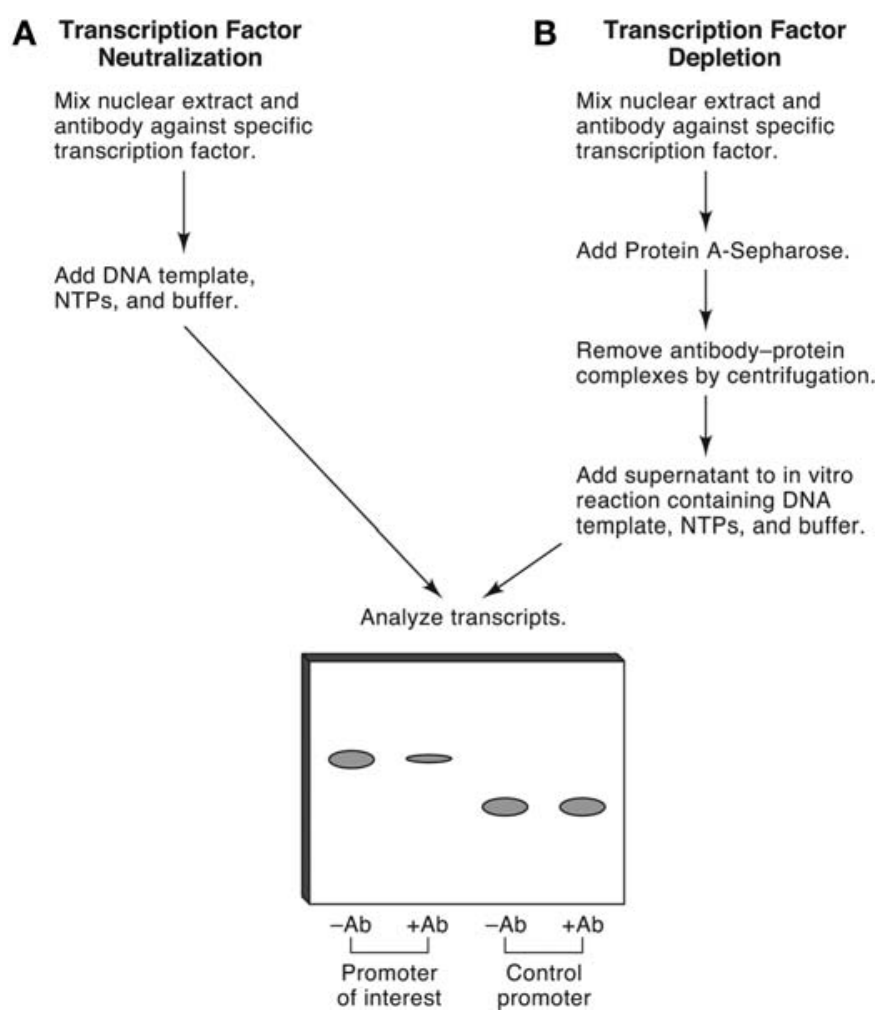

FIGURE 8. Assessing the relevance of a protein-DNA interaction by antibody inhibition of an in vitro transcription reaction.

In practice, depletion experiments to monitor the requirement for a protein in an in vitro transcription assay can be tedious and difficult. Depletion can inhibit the in vitro transcription assay nonspecifically because of extract dilution or inactivation of a general transcription factor. The protein bound by the antibody or DNA resin also has the potential to bind or form aggregates with other proteins that are essential for in vitro transcription, resulting in the codepletion of those proteins. These difficulties are not unusual because the extracts must be maintained in a concentrated state during depletion to function in the subsequent in vitro reactions.

Because of the potential problems with these types of experiments, careful controls are needed, including immunodepletion with antibodies that should have no effect on transcription from the promoter of interest, as well as control templates that should not be affected by the depletion. Furthermore, to show that specific inhibition is due solely to depletion of the protein of interest, it should be possible to restore transcription by complementing the reaction with a recombinant or pure form of the protein. When performed with well-designed controls and antibodies whose epitopes are readily accessible, depletion experiments can be quite successful. The results obtained using these in vitro approaches can support the functional importance of a protein for transcription of a target gene but cannot prove it conclusively. Again, a protein that functionally interacts with a control element in vitro is not necessarily responsible for its function in vivo.

Transcription factor depletion by immunoaffinity and DNA affinity chromatography was used for the in vitro transcription analysis of the IFN- $\beta$ promoter (Kim and Maniatis 1997). The activity of this promoter in vivo is believed to require ATF-2/c-Jun, an IRF family member, NF- $\kappa B$, and HMGA. To study the specific protein requirements for promoter function in vitro, an in vitro transcription assay dependent on the binding site for each factor was developed. Then, the first three factors were depleted by sequence-specific DNA affinity chromatography. Excess HMGA was depleted by immunoaffinity chromatography. Recombinant forms of each protein were added back to the depleted extracts, resulting in restored promoter activity. These results provided evidence that the specific proteins 
used are capable of activating the promoter. However, it should be noted that recombinant IRF-1 was used for these studies, whereas more recent findings strongly suggest that other IRF family members, in particular IRF-3 and IRF-7, are actually the relevant activators of IFN-B transcription (Wathelet et al. 1998; see above). Thus, the in vitro transcription method by itself is unreliable for showing the true in vivo relevance of a protein-DNA interaction.

Although this section has focused on protein neutralization and depletion in crude extracts, in vitro transcription can also be used as an assay for the unbiased purification of a protein that activates a promoter. A classic example of the use of this strategy led to the identification, purification, and cloning of a protein that stimulates the SV40 early promoter (Dynan and Tjian 1983a,b; Kadonaga et al. 1987). An in vitro transcription assay was first developed that supported accurate transcription from the promoter. The cell extract was then fractionated to identify an essential promoter-specific transcription factor. The factor identified, Sp1, was found to bind specific DNA sequence elements within the promoter. Sp1 was then purified, a partial peptide sequence was obtained, and its gene was cloned. The isolation of Sp1 as a protein that selectively activates the SV40 promoter in vitro provided reasonably strong support for the hypothesis that it is a relevant activator of the promoter in vivo.

\section{Altered-Specificity Experiments}

A final strategy for testing the relevance of a protein-DNA interaction is an altered-specificity strategy (Fig. 9). Although difficult to design and perform, this method has the potential to provide more compelling evidence that a protein-DNA interaction is relevant than any of the other strategies discussed in this article. To perform an altered-specificity experiment, the DNA-binding domain of the protein of interest is first mutated so that it recognizes a different DNA sequence. The new sequence recognized by the altered protein is then inserted into the control region of interest in place of the sequence element recognized by the wild-type protein. It is important for the new
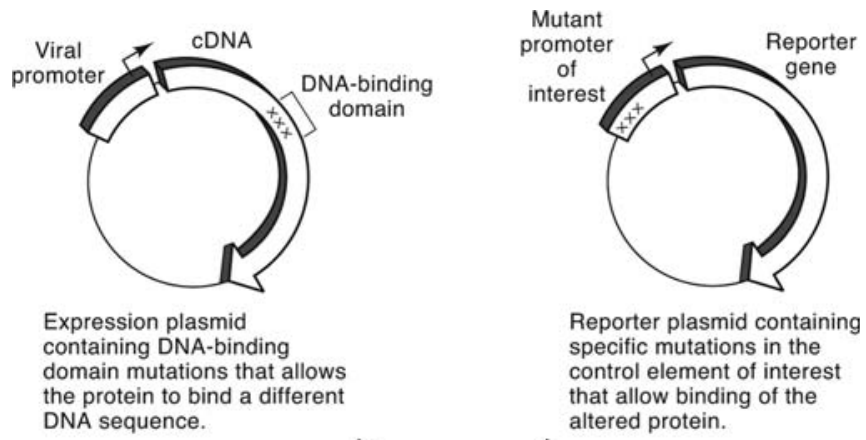

Reporter plasmid containing specific mutations in the control element of interest the protein to bind a different that allow binding of the DNA sequence.

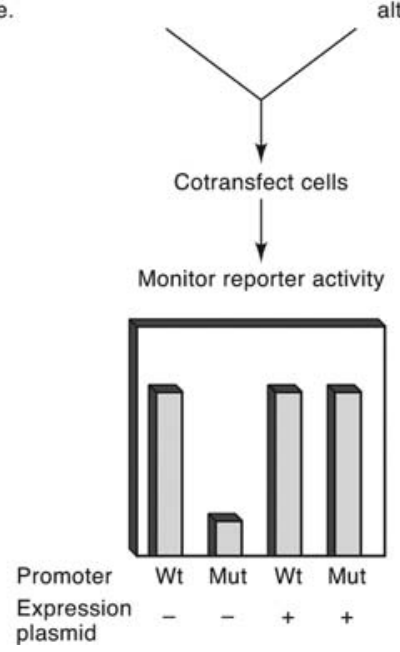
altered protein.

FIGURE 9. Altered-specificity strategy. 
recognition sequence to be fairly unique, so that it is not recognized with a significant affinity by other DNA-binding proteins within the cell. The altered-specificity DNA-binding protein is then expressed in cells containing an endogenous gene or reporter gene regulated by the altered control region, and its capacity to regulate transcription is monitored.

A particularly elegant example of an altered-specificity experiment, which reveals its strengths and weaknesses, was reported by Shah et al. (1997). (Another important example was reported by Gillemans et al. [1998].) The goal of this study was to determine which of two POU domain proteins, Oct-1 or Oct-2, functionally activate the Ig heavy- and light-chain gene promoters. Both proteins bind to the octamer elements within the Ig promoters with similar affinities and both proteins are expressed in B lymphocytes; gene disruption experiments had been uninformative. Therefore, it has been difficult to identify the relevant activator of the Ig promoters.

To create an altered-specificity Oct protein, Shah et al. (1997) examined the known crystal structure of the Oct-DNA complex. They focused on a particular amino acid sequence within the POU domain that contacted one of the nucleotides within the octamer DNA sequence. They mutated that nucleotide, disrupting binding by the wild-type Oct proteins. Then, they isolated an altered Oct POU domain capable of binding the altered DNA sequence with high affinity. To achieve this goal, they generated a phage expression library for the POU domain, in which each phage expressed a POU domain with a randomly generated amino acid sequence in the region that was predicted to be in close proximity to the altered base pair. To isolate phage that express a mutant POU domain capable of binding the altered DNA sequence, the expression library was probed with a radiolabeled oligonucleotide containing the altered sequence. The amino acids within the selected POU domain, which allowed high-affinity binding, were then determined and introduced into mammalian expression plasmids for both Oct-1 and Oct-2.

The altered Oct- 1 and Oct-2 proteins were tested in B cells for their ability to transactivate reporter plasmids under the control of Ig promoters containing the altered octamer DNA sequence. By using the altered octamer sequence, endogenous Oct- 1 and Oct- 2 proteins within the B cells were rendered nonfunctional on the Ig promoters; only the altered-specificity Oct-1 or Oct-2 introduced into the cells could bind. Because the experiments were performed in B cells, it was believed that the altered proteins would interact functionally with the other proteins needed for B-cell-specific Ig promoter and enhancer activity.

The results revealed that the altered Oct- 1 and Oct- 2 proteins were equally capable of stimulating Ig promoter activity. Surprisingly, however, when the reporter plasmids included an Ig enhancer in addition to the Ig promoter, Oct-1 was a much more potent activator. These results are consistent with a hypothesis in which Oct-1 is the functional activator of endogenous Ig genes, because only Oct- 1 can perform the protein-protein interactions needed for promoter- and enhancer-dependent transcription.

The altered-specificity strategy can provide compelling evidence that a DNA-binding protein acts at a particular target site. In effect, this method provides much of the same information as that provided by a gene disruption or RNAi experiment, but the key limitations of those experiments are eliminated. In gene disruption and RNAi studies, loss or knockdown of the DNA-binding protein can result in a loss of cell viability. In addition, it is extremely difficult to distinguish between direct and indirect effects of binding protein depletion or knockdown on the candidate target gene. The DNA-binding protein also may be redundant with a related protein, such that its absence has no effect on target gene transcription. Altered-specificity experiments avoid these limitations: The cells remain viable because the endogenous DNA-binding protein is still expressed, indirect effects are less likely because the altered recognition site for the altered-specificity protein has been introduced only into the control region of interest, and redundancy is not observed because the altered DNA-binding domain is present in only one protein.

Despite these advantages, the altered-specificity approach also has three limitations. The procedure typically involves overexpression of the altered DNA-binding protein by either transient or stable transfection. As discussed previously, results obtained with overexpressed proteins are inconclusive and difficult to interpret. To enhance the validity of the results of an altered-specificity experiment, the 
altered protein should be expressed at a concentration similar to that of the endogenous, wild-type protein. To achieve this, different stable cell lines expressing the altered protein can be examined, or a variety of expression vectors containing different promoters or enhancers can be tested.

The second limitation arises when the altered control region is analyzed in the context of a transiently transfected reporter plasmid. The high copy number of the reporter plasmid and its removal from its natural chromosomal environment could influence its ability to respond to the altered-specificity protein. Ideally, the substitution mutation creating the altered control element would be introduced into the endogenous gene by homologous recombination. This rigorous approach would provide the strongest evidence that a particular DNA-binding protein acts on a target gene. Of course, this experiment requires much more effort than the basic transfection experiment. The use of a stably transfected reporter plasmid is preferred to the use of a transiently transfected reporter, but the results would remain inconclusive.

The third limitation, which cannot be overcome, is that the transcriptional activation function of the wild-type DNA-binding protein might depend on the specific amino acids that are altered. These amino acids could be involved directly in transcriptional activation, or the protein-DNA interaction could lead to a conformational change in another surface of the protein involved in transcriptional activation. In most altered-specificity DNA-binding proteins, the amino acids responsible for DNA binding are unimportant for transcriptional activation, but examples of a conformational link between DNA binding and activation have been described (Lefstin and Yamamoto 1998). Nevertheless, despite these limitations, altered-specificity experiments can provide valuable information regarding the relevance of a protein-DNA interaction and hold an important position among the arsenal of strategies described in this article.

We have described 12 general strategies that can be used to examine whether a specific protein directly regulates a target gene by binding to a defined control element. Some of these strategies might not be feasible for analysis of some DNA-binding proteins, and other strategies not described can be envisioned (e.g., in vivo antibody microinjection experiments). No single approach can establish conclusively the functional relevance of a protein-DNA interaction. However, a hypothesis can be strengthened greatly by subjecting it to as many rigorous tests as possible.

\section{REFERENCES}

Amarzguioui M, Lundberg P, Cantin E, Hagstrom J, Behlke MA, Rossi JJ. 2006. Rational design and in vitro and in vivo delivery of Dicer substrate siRNA. Nat Protoc 1: 508-517.

Anderson E, Boese Q, Khvorova A, Karpilow J. 2008. Identifying siRNAinduced off-targets by microarray analysis. Methods Mol Biol 442: 45-63.

Barton GM, Medzhitov R. 2002. Retroviral delivery of small interfering RNA into primary cells. Proc Natl Acad Sci 99: 14943-14945.

Beima KM, Miazgowicz MM, Lewis MD, Yan PS, Huang TH, Weinmann AS. 2006. T-bet binding to newly identified target gene promoters is cell type-independent but results in variable context-dependent functional effects. J Biol Chem 281: 11992-12000.

Benezra R, Davis RL, Lockshon D, Turner DL, Weintraub H. 1990. The protein Id: A negative regulator of helix-loop-helix binding proteins. Cell 61: 49-59.

Boyd KE, Farnham PJ. 1997. Myc versus USF: Discrimination at the cad gene is determined by core promoter elements. Mol Cell Biol 17: 2529-2537.

Boyd KE, Wells J, Gutman J, Bartley SM, Farnham PJ. 1998. c-Myc target gene specificity is determined by a post-DNA-binding mechanism. Proc Natl Acad Sci 95: 13887-13892.

Bradley MN, Zhou L, Smale ST. 2003. C/EBPb regulation in lipo-poly-saccharide-stimulated macrophages. Mol Cell Biol 23: 4841-4858.
Branch AD. 1998. A good antisense molecule is hard to find. Trends Biochem Sci 23: 45-50.

Braunstein M, Rose AB, Holmes SG, Allis CD, Broach JR. 1993. Transcriptional silencing in yeast is associated with reduced nucleosome acetylation. Genes Dev 7: 592-604.

Brummelkamp TR, Bernards R, Agami R. 2002. A system for stable expression of short interfering RNAs in mammalian cells. Science 296: 550-553.

Capecchi MR. 1989. Altering the genome by homologous recombination. Science 244: 1288-1292.

Capecchi MR. 2005. Gene targeting in mice: Functional analysis of the mammalian genome for the twenty-first century. Nat Rev Genet 6: 507-512.

Clevers HC, Grosschedl R. 1996. Transcriptional control of lymphoid development: Lessons from gene targeting. Immunol Today 17: 336-343.

Cullen BR. 2006. Enhancing and confirming the specificity of RNAi experiments. Nat Methods 3: 677-681.

Descombes P, Schibler U. 1991. A liver-enriched transcriptional activator protein, LAP, and a transcriptional inhibitory protein, LIP, are translated from the same mRNA. Cell 67: 569-579.

Dong J, Jimi E, Zhong H, Hayden MS, Ghosh S. 2008. Repression of gene expression by unphosphorylated NF- $<$ gk $>$ B p 65 through epigenetic mechanisms. Genes Dev 22: 1159-1173. 
Dynan WS, Tjian R. 1983a. Isolation of transcription factors that discriminate between different promoters recognized by RNA polymerase II. Cell 32: 669-680.

Dynan WS, Tjian R. 1983b. The promoter-specific transcription factor Spl binds to upstream sequences in the SV40 early promoter. Cell 35: 79-87.

Eisenbeis CF, Singh H, Storb U. 1995. Pip, a novel IRF family member, is a lymphoid-specific, PU.1-dependent transcriptional activator. Genes Dev 9: 1377-1387.

Elbashir SM, Lendeckel W, Tuschl T. 2001a. RNA interference is mediated by 21- and 22-nucleotide RNAs. Genes Dev 15: 188-200.

Elbashir SM, Harborth J, Lendeckel W, Yalcin A, Weber K, Tuschl T. 2001b. Duplexes of 21-nucleotide RNAs mediate RNA interference in cultured mammalian cells. Nature 411: 494-498.

Elbashir SM, Harborth J, Weber K, Tuschl T. 2002. Analysis of gene function in somatic mammalian cells using small interfering RNAs. Methods 26: 199-213.

Ernst P, Hahm K, Smale ST. 1993. Both LyF-1 and an Ets protein interact with a critical promoter element in the murine terminal transferase gene. Mol Cell Biol 13: 2982-2992.

Ernst P, Hahm K, Trinh L, Davis JN, Roussel MF, Turck CW, Smale ST. 1996. A potential role for Elf- 1 in terminal transferase gene regulation. Mol Cell Biol 16: 6121-6131.

Fiering S, Northrop JP, Nolan GP, Mattila PS, Crabtree GR, Herzenberg LA. 1990. Single cell assay of a transcription factor reveals a threshold in transcription activated by signals emanating from the T-cell antigen receptor. Genes Dev 4: 1823-1834.

Fire A, Xu S, Montgomery MK, Kostas SA, Driver SE, Mello CC. 1998. Potent and specific genetic interference by double-stranded RNA in Caenorhabditis elegans. Nature 391: 806-811.

Folger K, Thomas K, Capecchi MR. 1984. Analysis of homologous recombination in cultured mammalian cells. Cold Spring Harbor Symp Quant Biol 49: 123-138.

to Georgopoulos K, Moore DD, Derfler B. 1992. Ikaros, an early lymphoidspecific transcription factor and a putative mediator for $\mathrm{T}$ cell commitment. Science 258: 808-812.

Gillemans N, Tewari R, Lindeboom F, Rottier R, de Wit T, Wijgerde M, Grosveld F, Philipsen S. 1998. Altered DNA-binding specificity mutants of EKLF and Sp1 show that EKLF is an activator of the $<\mathrm{gb}>$-globin locus control region in vivo. Genes Dev 12: 2863-2873.

Gilmour DS, Lis JT. 1984. Detecting protein-DNA interactions in vivo: Distribution of RNA polymerase on specific bacterial genes. Proc Natl Acad Sci 81: 4275-4279.

Gilmour DS, Lis JT. 1985. In vivo interactions of RNA polymerase II with genes of Drosophila melanogaster. Mol Cell Biol 5: 2009-2018.

Gilmour DS, Lis JT. 1986. RNA polymerase II interacts with the promoter region of the noninduced hsp70 gene in Drosophila melanogaster cells. Mol Cell Biol 6: 3984-3989.

Gu H, Marth JD, Orban PC, Mossmann H, Rajewsky K. 1994. Deletion of a DNA polymerase $B$ gene segment in $\mathrm{T}$ cells using cell type-specific gene targeting. Science 265: 103-106.

Hahm K, Ernst P, Lo K, Kim GS, Turck C, Smale ST. 1994. The lymphoid transcription factor LyF-1 is encoded by specific, alternatively-spliced mRNAs derived from the Ikaros gene. Mol Cell Biol 14: 7111-7123.

He L, Hannon GJ. 2004. MicroRNSa: Small RNAs with a big role in gene regulation. Nat Rev Genet 5: 522-531.

Hecht A, Grunstein M. 1999. Mapping DNA interaction sites of chromosomal proteins using immunoprecipitation and polymerase chain reaction. Methods Enzymol 304: 399-414.

Hecht A, Strahl-Bolsinger S, Grunstein M. 1996. Spreading of transcriptional repressor SIR3 from telomeric heterochromatin. Nature 383: 92-96.

Hollenhorst PC, Jones DA, Graves BJ. 2004. Expression profiles frame the promoter specificity dilemma of the ETS family of transcription factors. Nucleic Acids Res 32: 5693-5702.

Hollenhorst PC, Shah AA, Hopkins C, Graves BJ. 2007. Genome-wide analyses reveal properties of redundant and specific promoter occupancy within the ETS gene family. Genes Dev 21: 1882-1894.

Jonsen MD, Petersen JM, Xu QP, Graves BJ. 1996. Characterization of the cooperative function of inhibitory sequences in Ets-1. Mol Cell Biol 16: 2065-2073.

Kadonaga JT, Carner KR, Masiarz FR, Tjian R. 1987. Isolation of cDNA encoding transcription factor $\mathrm{Sp} 1$ and functional analysis of the DNA binding domain. Cell 51: 1079-1090.
Kim TK, Maniatis M. 1997. The mechanism of transcriptional synergy of an in vitro assembled interferon- $<\mathrm{gb}>$ enhanceosome. Mol Cell 1: 119-129.

Kim DH, Rossi JJ. 2007. Strategies for silencing human disease using RNA interference. Nat Rev Genet 8: 173-184.

Krylov D, Kasai K, Echlin DR, Taparowsky EJ, Arnheiter H, Vinson C. 1997. A general method to design dominant negatives to B-HLHZip proteins that abolish DNA binding. Proc Natl Acad Sci 94: 12274-12279.

Langlands K, Yin X, Anand G, Prochownik EV. 1997. Differential interactions of Id proteins with basic helix-loop-helix transcription factors. J Biol Chem 272: 19785-19793.

Lassus P, Rodriguez J, Lazebnik Y. 2002. Confirming specificity of RNAi in mammalian cells. Sci STKE 147: PL13.

Lauring J, Schlissel MS. 1999. Distinct factors regulate the murine RAG-2 promoter in B and T cell lines. Mol Cell Biol 19: 2601-2612.

Lee GM, Donaldson LW, Pufall MA, Kang HS, Pot I, Graves BJ, McIntosh LP. 2005. The structural and dynamic basis of Ets-1 DNA binding autoinhibition. J Biol Chem 280: 7088-7099.

Lefstin JA, Yamamoto KR. 1998. Allosteric effects of DNA on transcriptional regulators. Nature 392: 885-888.

Lehman AM, Ellwood KB, Middleton BE, Carey M. 1998. Compensatory energetic relationships between upstream activators and the RNA polymerase II general transcription machinery. J Biol Chem 273: 932-939.

Li Q, Johnston SA. 2001. Are all DNA binding and transcription regulation by an activator physiologically relevant? Mol Cell Biol 21: 2467-2474.

Lipston KE, Baserga R. 1989. Transcriptional activity of the human thymidine kinase gene determined by a method using the polymerase chain reaction and an intron-specific probe. Proc Natl Acad Sci 86: 9774-9777.

Lo K, Landau NR, Smale ST. 1991. LyF-1, a transcriptional regulator that interacts with a novel class of promoters for lymphocyte-specific genes. Mol Cell Biol 11: 5229-5243.

Lodish H, Baltimore D, Berk A, Zipursky SL, Darnell J. 1996. Molecular cell biology, 3rd ed. W.H. Freeman, New York.

Martone R, Euskirchen G, Bertone P, Hartman S, Royce TE, Luscombe NM, Rinn JL, Nelson FK, Miller P, Gerstein M, et al. 2003. Distribution of NF- $<$ gk $>$ B-binding sites across human chromosome 22. Proc Natl Acad Sci 100: 12247-12252.

Mauxion F, Jamieson C, Yoshida M, Arai K, Sen R. 1991. Comparison of constitutive and inducible transcriptional enhancement mediated by $<$ gk $>$ B-related sequences: Modulation of activity in B cells by human T-cell leukemia virus type I tax gene. Proc Natl Acad Sci 88: 2141-2145.

Miyagishi M, Taira K. 2002. U6 promoter-driven siRNAs with four uridine $3^{\prime}$ overhangs efficiently suppress targeted gene expression in mammalian cells. Nat Biotechnol 20: 497-500.

Okamura RM, Sigvardsson M, Galceran J, Verbeek S, Clevers H, Grosschedl R. 1998. Redundant regulation of T cell differentiation and TCR $<$ ga $>$ gene expression by the transcription factors LEF-1 and TCF-1. Immunity 8: $11-20$

Olive M, Williams SC, Dezan C, Johnson PF, Vinson C. 1996. Design of a C/ EBP-specific, dominant-negative bZIP protein with both inhibitory and gain-of-function properties. J Biol Chem 271: 2040-2047.

Orlando V, Paro R. 1993. Mapping Polycomb-repressed domains in the bithorax complex using in vivo formaldehyde cross-linked chromatin. Cell 75: 1187-1198.

Orlando V, Strutt H, Paro R. 1997. Analysis of chromatin structure by in vivo formaldehyde cross-linking. Methods 11: 205-214.

Paddison PJ. 2008. RNA interference in mammalian cell systems. Curr Top Microbiol Immunol 320: 1-19.

Paddison PJ, Caudy AA, Bernstein E, Hannon GJ, Conklin DS. 2002. Short hairpin RNAs (shRNAs) induce sequence-specific silencing in mammalian cells. Genes Dev 16: 948-958.

Panne D, Maniatis T, Harrison SC. 2007. An atomic model of the interferon$<\mathrm{gb}>$ enhanceosome. Cell 129: 1111-1123.

Parekh BS, Maniatis T. 1999. Virus infection leads to localized hyperacetylation of histones $\mathrm{H} 3$ and $\mathrm{H} 4$ at the IFN- $<\mathrm{gb}>$ promoter. Mol Cell 3 $125-129$.

Paul CP, Good PD, Winer I, Engelke DR. 2002. Effective expression of small interfering RNA in human cells. Nat Biotechnol 20: 505-508.

Pei Y, Tuschl T. 2006. On the art of identifying effective and specific siRNAs. Nat Methods 3: 670-676. 
Phuc Le P, Friedman JR, Schug J, Brestelli JE, Parker JB, Bochkis IM, Kaestner KH. 2005. Glucocorticoid receptor-dependent gene regulatory networks. PLoS Genet 1: e16.

Plevy SE, Gemberling J, Hsu S, Dorner AJ, Smale ST. 1997. Multiple control elements mediate activation of the murine and human IL-12 p40 promoters: Evidence of functional synergy between C/EBP and Rel proteins. Mol Cell Biol 17: 4572-4588.

Pongubala JM, Nagulapalli S, Klemsz MJ, McKercher SR, Maki RA, Atchison ML. 1992. PU.1 recruits a second nuclear factor to a site important for immunoglobulin $<\mathrm{gk}>3^{\prime}$ enhancer activity. Mol Cell Biol 12 368-378.

Pufall MA, Lee GM, Nelson ML, Kang HS, Velyvis A, Kay LE, McIntosh LP, Graves BJ. 2005. Variable control of Ets-1 DNA binding by multiple phosphates in an unstructured region. Science 309: 142-145.

Reddy ST, Gilbert RS, Xie W, Luner S, Herschman HR. 1994. TGF-<gb> inhibits both endotoxin-induced prostaglandin synthesis and expression of the TIS10/prostaglandin synthase 2 gene in murine macrophages. J Leukoc Biol 55: 192-200.

Rishi V, Vinson C. 2003. Dominant-negative mutants of helix-loophelix proteins: Transcriptional inhibition. Methods Enzymol 370: 454-466.

Rundlett SE, Carmen AA, Suka N, Turner BM, Grunstein M. 1998. Transcriptional repression by UME6 involves deacetylation of lysine 5 of histone H4 by RPD3. Nature 392: 831-835.

Sen GL, Blau HM. 2006. A brief history of RNAi: The silence of the genes. FASEB J 20: 1293-1299.

Shah PC, Bertolino E, Singh H. 1997. Using altered specificity Oct-1 and Oct-2 mutants to analyze the regulation of immunoglobulin gene transcription. EMBO J 16: 7105-7117.

Smithies O, Gregg RG, Boggs SS, Koralewski MA, Kucherlapati RS 1985. Insertion of DNA sequences into the human chromosomal $<$ gb $>$-globin locus by homologous recombination. Nature 317: $230-234$.

Snøve O Jr, Rossi JJ. 2006. Expressing short hairpin RNAs in vivo. Nat Methods 3: 689-695.
Solomon MJ, Varshavsky A. 1985. Formaldehyde-mediated DNA-protein crosslinking: A probe for in vivo chromatin structures. Proc Natl Acad Sci 82: 6470-6474.

Solomon MJ, Larsen PL, Varshavsky A. 1988. Mapping protein-DNA interactions in vivo with formaldehyde: Evidence that histone $\mathrm{H} 4$ is retained on a highly transcribed gene. Cell 53: 937-947.

Stein CA. 1998. How to design an antisense oligodeoxynucleotide experiment: A consensus approach. Antisense Nucleic Acid Drug Dev 8: $129-132$.

Svoboda P. 2007. Off-targeting and other non-specific effects of RNAi experiments in mammalian cells. Curr Opin Mol Ther 9: 248-257.

Thanos D, Maniatis T. 1995a. Virus induction of human IFN $<\mathrm{Gb}>$ gene expression requires the assembly of an enhanceosome. Cell 83: $1091-1100$.

Thanos D, Maniatis T. 1995b. NF-<gk>B: A lesson in family values. Cell 80: $529-532$.

Thomas KR, Capecchi MR. 1987. Site-directed mutagenesis by gene targeting in mouse embryo-derived stem cells. Cell 51: 503-512.

van Genderen C, Okamura RM, Farinas I, Quo RG, Parslow TG, Bruhn L, Grosschedl R. 1994. Development of several organs that require inductive epithelial-mesenchymal interactions is impaired in LEF-1-deficient mice. Genes Dev 8: 2691-2703.

Verbeek S, Izon D, Hofhuis F, Robanus-Maandag E, te Riele H, van de Wetering M, Oosterwegel M, Wilson A, MacDonald HR, Clevers $\mathrm{H}$. 1995. An HMG-box-containing T-cell factor required for thymocyte differentiation. Nature 374: 70-74.

Walter J, Dever CA, Biggin MD. 1994. Two homeo domain proteins bind with similar specificity to a wide range of DNA sites in Drosophila embryos. Genes Dev 8: 1678-1692.

Wathelet MG, Lin CH, Parekh BS, Ronco LV, Howley PM, Maniatis T. 1998. Virus infection induces the assembly of coordinately activated transcription factors on the IFN- $<\mathrm{gb}>$ enhancer in vivo. Mol Cell 1: 507-518.

Wiznerowicz M, Szulc J, Trono D. 2006. Tuning silence: Conditional systems for RNA interference. Nat Methods 3: 682-688. 


\title{
Confirming the Functional Importance of a Protein-DNA Interaction
}

\author{
Michael F. Carey, Craig L. Peterson and Stephen T. Smale
}

Cold Spring Harb Protoc; doi: 10.1101/pdb.top070060

\begin{tabular}{rc}
\hline $\begin{array}{c}\text { Email Alerting } \\
\text { Service }\end{array}$ & Receive free email alerts when new articles cite this article - click here. \\
\hline $\begin{array}{c}\text { Subject } \\
\text { Categories }\end{array}$ & Browse articles on similar topics from Cold Spring Harbor Protocols. \\
& Analysis of Gene Expression, general (129 articles) \\
& DNA:Protein Interactions (74 articles) \\
& Immunoprecipitation (75 articles) \\
& Molecular Biology, general (1293 articles) \\
& Protein Expression and Interactions (93 articles) \\
& Protein Identification and Analysis (202 articles) \\
& RNA Interference (RNAi)/siRNA (123 articles) \\
\hline
\end{tabular}

